\title{
Slightly beneficial genes are retained by evolving Horizontal Gene Transfer despite selfish elements
}

\author{
B. van Dijk ${ }^{1} \mid$ P. Hogeweg ${ }^{1} \mid$ H.M. Doekes ${ }^{1} \mid$ N. Takeuchi² \\ $1=$ Utrecht University, Theoretical Biology, the Netherlands \\ $2=$ University of Auckland, School of Biological Sciences, New Zealand \\ Correspondence: B. van Dijk (bramvandijk88@gmail.com), P. Hogeweg (p.hogeweg@uu.nl)
}

\begin{abstract}
Horizontal gene transfer (HGT) is a key component of bacterial evolution, which in concert with gene loss can result in rapid changes in gene content. While HGT can evidently aid bacteria to adapt to new environments, it also carries risks since bacteria may pick up selfish genetic elements (SGEs). Here, we use modeling to study how bacterial growth rates are affected by HGT of slightly beneficial genes, if bacteria can evolve HGT to improve their growth rates, and when HGT is evolutionarily maintained in light of harmful SGEs. We find that we can distinguish between four classes of slightly beneficial genes: indispensable, enrichable, rescuable, and unrescuable genes. Rescuable genes - genes that confer small fitness benefits and are lost from the population in the absence of $\mathrm{HGT}$ - can be collectively retained by a bacterial community that engages in HGT. While this 'gene-sharing' cannot evolve in well-mixed cultures, it does evolve in a spatially structured population such as a biofilm. Although HGT does indeed enable infection by harmful SGEs, HGT is nevertheless evolutionarily maintained by the hosts, explaining the stable coexistence and co-evolution of bacteria and SGEs.
\end{abstract}


bioRxiv preprint doi: https://doi.org/10.1101/2020.02.13.947077; this version posted February 16, 2020. The copyright holder for this preprint (which was not certified by peer review) is the author/funder. All rights 2 reserved. No reuse allowed without permission.

\section{Introduction}

Horizontal Gene Transfer (HGT), the transmission of genetic material between unrelated individuals, is a major factor driving prokaryotic evolution (Ochman et al. 2000, Doolittle and Zhaxybayeva, 2009, Vogan and Higgs, 2011). Recent estimates of the rate of HGT in closely related bacteria are staggeringly high (Iranzo et al. 2019. Sakoparnig et al. 2019), with HGT possibly even outpacing gradual sequence evolution (Hao and Golding 2006 . Puigbò et al. 2014, Vos et al. , 2015). Combining this with the fact that prokaryotes adapt mostly through rapid gene loss (Kuo and Ochman 2009, Morris et al. 2012), bacterial adaptation appears to be mainly driven by changes in gene content (Snel et al.| 2002, Treangen and Rocha) 2011 Nowell et al. 2014). Rather than waiting for rare beneficial mutations to arise, taking up tried-and-true genes from a shared 'mobile gene pool' allows bacteria to adapt quickly to different ecological opportunities (Jain et al. 2003, Wiedenbeck and Cohan, 2011: Casacuberta and González 2013. Mell and Redfield||2014 Niehus et al. |2015 | Lopatkin et al. |2016). Indeed, many bacterial species show patterns consistent with this rapid turn-over of genes, where strains from a single niche contain a relatively small set of genes, while the set of genes found by sampling strains from various niches (i.e. the pan-genome) is much richer (Welch et al. 2002, Lefébure and Stanhope, 2007, Touchon et al. 2009, Kim et al. 2015). Hence, genes appear to be rapidly lost from any individual lineage, but are retained in a much larger gene pool through HGT.

When considering the effects of HGT on gene content, it is important to note that HGT does not only recombine genes, but also has the ability to copy genes from one individual to another. The latter process has been referred to as "additive HGT" (Thomas and Nielsen, 2005, Choi et al. 2012 Soucy et al. 2015), and is quite distinct from processes like sex and recombination because genes can now replicate independently from the cell cycle, and can thus spread at their own pace (Hall et al. 2016, Nazarian et al. 2018, Takeuchi et al. 2015 Shapiro et al. 2012). In additive HGT, a host cell picks up genes either from other cells or from the environment, which may subsequently be expressed. Aside from the cost of expressing the machinery to do so, this process also poses a risk in the form of Selfish Genetic Elements (SGEs), whose success may depend on their ability to be transferred to new hosts (Bergstrom et al. 2000, Lili et al. 2007. Slater et al. 2008). Hence, while picking up genes can be very beneficial for bacteria when adapting to a new environment (Casacuberta and González, 2013, Mell and Redfield, 2014, Lopatkin et al. 2016), taking up foreign DNA is also a costly and highly risky endeavour (Vogan and Higgs, 2011:|Baltrus, 2013). Given these disadvantages, is HGT ever adaptive for bacteria when the environment does not change? Can HGT be considered an evolved trait of bacteria, or is it only a side-effect of other unrelated processes like infection by SGEs or DNA repair (Redfield, 2001)?

To address these questions, we here present and analyse a model of a bacterial population undergoing additive HGT of a single gene, where we assume that HGT is a costly process for the host cells. We show that HGT can have a positive impact on population growth rates by recovering slightly beneficial genes, which are hard to maintain in the population through selection alone. Based on whether or not the genes are lost from the population without HGT, and whether HGT can improve the population growth rate, we find that genes fall into one of five gene classes: (i) indispensable genes, that are never lost from the population, and for which HGT is therefore unnecessary and deleterious, (ii) enrichable genes, that are not lost from the population, but enriching the genes via HGT can nevertheless improve growth rates, (iii) rescuable genes, which are lost from the population without HGT, but can be rescued by HGT which improves population growth rates, (iv) unrescuable genes which are also lost from the population without HGT, but recovering them with HGT does not improve growth rates, and (v) selfish genetic elements, which confer a fitness penalty but can persist through HGT. For 
bioRxiv preprint doi: https://doi.org/10.1101/2020.02.13.947077; this version posted February 16, 2020. The

copyright holder for this preprint (which was not certified by peer review) is the author/funder. All rights reserved. No reuse allowed without permission.

enrichable and rescuable genes, where HGT can increase population growth rates, we also investigate if HGT can evolve de novo. While HGT can readily evolve for enrichable genes, which have sufficient donor cells to interact with, evolving HGT to 'rescue' rescuable genes faces a problem: HGT is needed for the gene to persist in the population, but sufficient donor cells are required to make HGT adaptive. This paradox is however resolved in a spatially structured population like a biofilm, as even a minority of donor cells can be locally abundant, giving rise to a localised 'gene-sharing' community that eventually overgrows the whole population. Finally, in this spatial eco-evolutionary context, HGT is evolutionarily maintained even when exploited by harmful genetic parasites, resulting in stable coexistence of bacteria and SGEs. Our model provides important insights and search images for how slightly beneficial genes may spread, or fail to spread, in an evolving microbial population. 
bioRxiv preprint doi: https://doi.org/10.1101/2020.02.13.947077; this version posted February 16, 2020. The copyright holder for this preprint (which was not certified by peer review) is the author/funder. All rights 4

reserved. No reuse allowed without permission.

\section{Results}

Throughout this study, we analyse how the ability of HGT affects the growth rates of bacterial populations, and to what extent the ability of HGT is evolvable for the host cells. We do so by considering a 'hard case', where HGT is a continuously costly process for all cells, and is only beneficial under specific circumstances. Consider two cell types: cells that carry a beneficial gene (carriers, $C$ ), and cells that do not (non-carriers, $N$ ). The benefit of carrying the gene, $b$, makes carriers grow faster than non-carriers (or slower if $b<0$, i.e. the gene is a selfish element), but carriers lose the beneficial gene at a fixed rate $l$. Non-carriers can recover genes by interacting with carriers through HGT. We have studied these dynamics with different models, first using simple ordinary differential equations (ODEs, Figure 1/A/B), and later an individual-based model that takes spatial population structuring into account (IBM, Figure 1.C). The equations and full description of the models can be found in the Methods section.

A) ODE model (carriers and non-carriers)

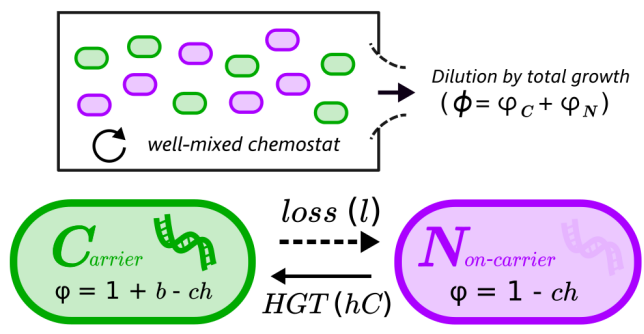

Q: How does HGT impact the population growth rate?

B) ODE model (carriers and non-carriers with / without HGT)

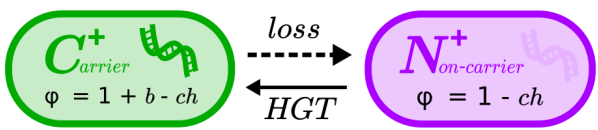

Proportional to total carriers $\left(\boldsymbol{C}^{+}+\boldsymbol{C}^{-}\right)$

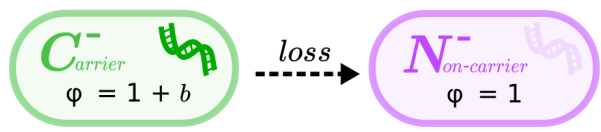

Dilution by total growth $\phi=\left(\varphi_{C^{+}}+\varphi_{N^{+}}+\varphi_{C^{-}}+\varphi_{N^{-}}\right)$

Q: Is HGT evolutionarily stable? Can HGT evolve de novo?
C) Individual-based, eco-evolutionary model

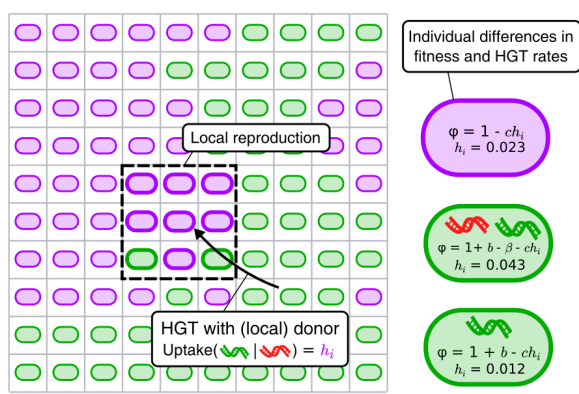

Q: What is the impact of spatial structure?

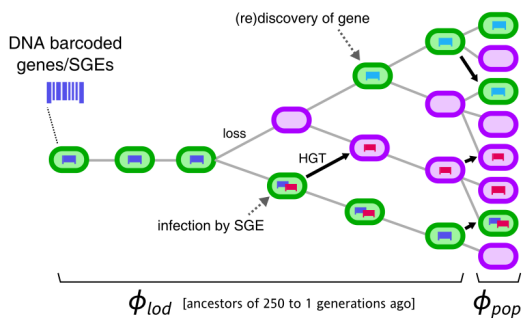

Q: Can genes / SGEs spread through a community? Is HGT maintained in the presence of harmful SGEs?

Figure 1: Graphical overviews of the different models: This study uses a series of models with gradually increasing complexity. The first two models are composed of Ordinary Differential Equations (ODEs), and the third model is an individual-based model (IBM). The models describe a population of bacterial cells which either carry a beneficial gene (carriers, $\boldsymbol{C}$ ) or do not carry the genes (non-carriers, $\boldsymbol{N}$ ). The cells are competing for a limited resource, where the intrinsic growth is $1, b$ is the growth rate advantage (or disadvantage) for carrying the gene, $l$ is the rate at which the gene is lost, $h$ is the rate of HGT, $c$ is the cost of HGT, $\varphi$ is the growth rate of sub-populations / individual cells, and $\phi$ represents the total growth rate. The IBM makes a distinction between the average growth rate of the population $\left(\phi_{p o p}\right)$ and the average growth rate of the line of descent ( $\phi_{\text {lod }}$, previous 250 generations of cells). In the IBM, both beneficial genes (with benefit $\boldsymbol{b}$, green) and harmful selfish genetic elements (SGEs, red) with a fitness penalty $\boldsymbol{\beta}$ are taken into account. Genes and SGEs are tagged with a unique barcode when they flux in, which are inherited upon reproduction or transfer. Parameters $\boldsymbol{c}, \boldsymbol{h}$ and $\boldsymbol{l}$ are assumed to be positive. 
bioRxiv preprint doi: https://doi.org/10.1101/2020.02.13.947077; this version posted February 16, 2020. The copyright holder for this preprint (which was not certified by peer review) is the author/funder. All rights reserved. No reuse allowed without permission.

A)

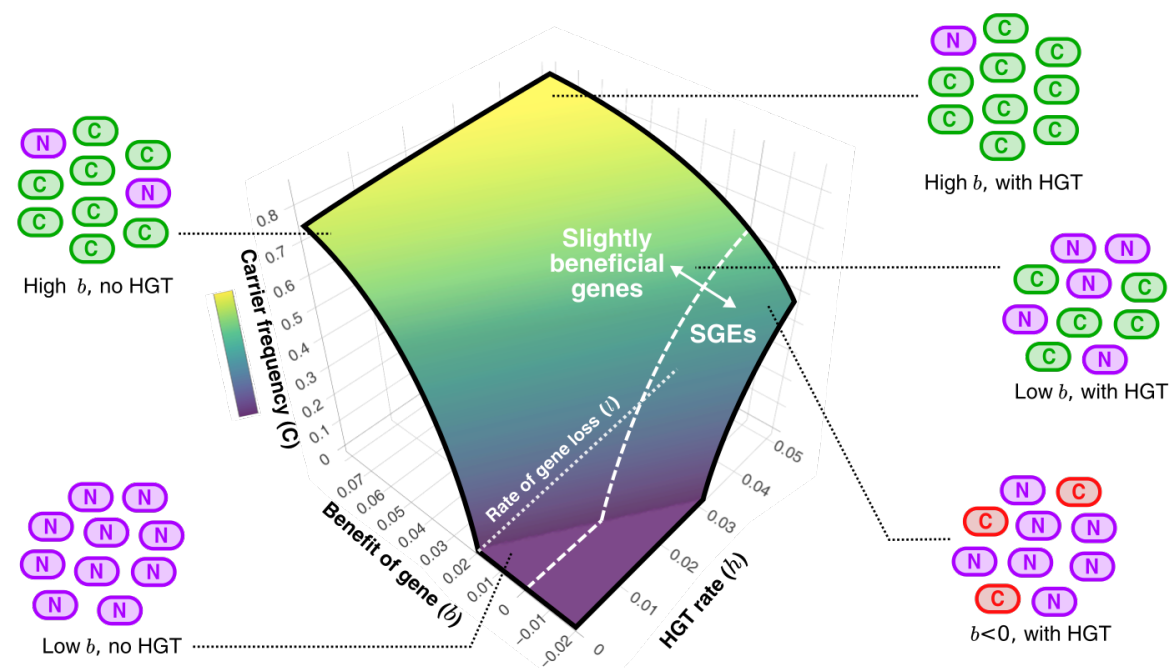

B)

\section{Indispensable genes \\ These genes are readily maintained. Transferring these genes with costly HGT always diminishes the growth rate of the population.}

Enrichable genes

These genes are maintained without HGT, but HGT can improve the population growth rate.

\section{Rescuable genes}

These genes are lost from the population without HGT. If the rate of HGT is high enough, the genes persist and the population growth rate is improved.

\section{Unrescuable genes}

These genes are lost from the population without HGT. Despite being maintained at intermediate rates of HGT, the population grows fastest without $\mathrm{HGT}$.

\section{Selfish genetic elements}

Selfish genetic elements (SGEs) can only persist at very high rates of HGT. When they do, the population growth rate is diminished.
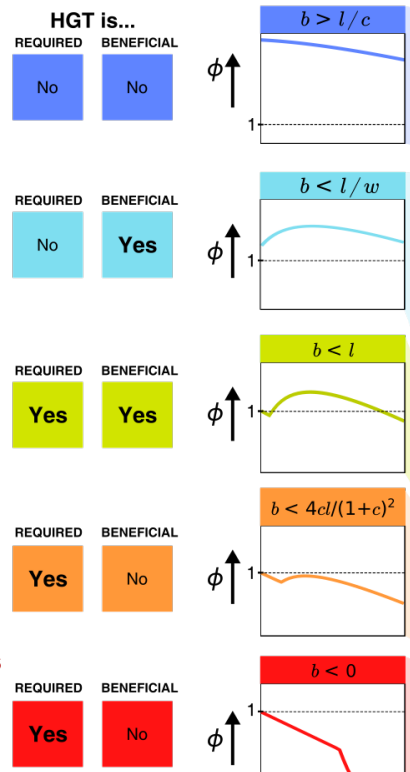

C)

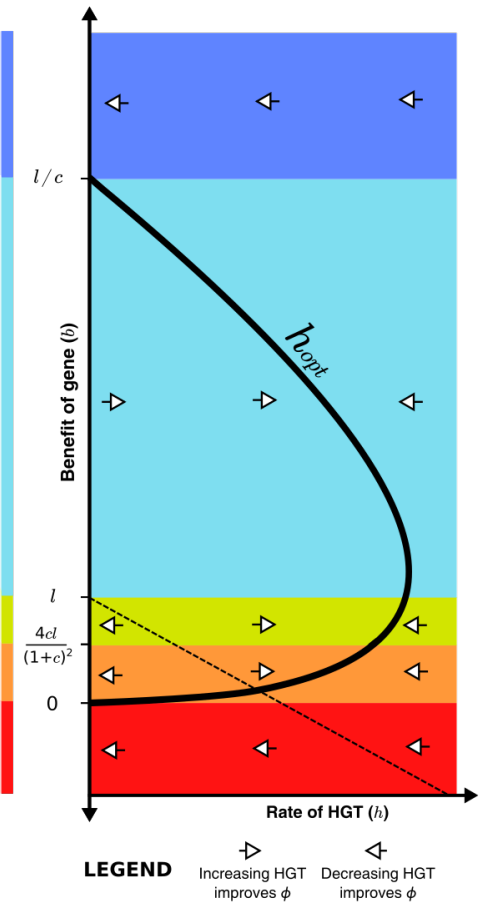

Figure 2: HGT can help genes persist in the population, resulting in distinct gene classes of slightly beneficial genes A) The frequency of carrier cells is shown in a 3D surface plot for different values of $b$ and $h$. This function is derived in the Supplementary Material and given by Equation 10 and here drawn for $l=0.02$ and $c=0.2$. The white dashed line $(b=0)$ gives the boundary between slightly beneficial genes and selfish genetic elements (SGEs). Cartoons illustrate how, for a very beneficial gene (high $b$ ), HGT leads only to a mild increase in carrier cells, how HGT has a large impact when the gene brings a smaller fitness effect (low $b$ ), and how SGEs can also persist with high HGT rates $(b<0)$. B) Different classes of slightly beneficial genes can be distinguished based on (i) if HGT is required for the gene to persist within the population and (ii) if HGT is beneficial for population growth rates. The graphs on the right-hand side show, for each of these classes, how an increasing rate of HGT (x-axis) influences the population growth $\phi$ (y-axis). C) A bifurcation diagram shows how the population growth rate is either improved or diminished by HGT for different values of the rate of HGT ( $h, \mathrm{x}$-axis) and the benefit parameter $(b, \mathrm{y}$-axis). The HGT rate that optimises population growth rates $\left(h_{o p t}=\sqrt{b l / c}-b\right)$ is depicted by the thick black curve. The dashed line is given by $h=l-b$, above which the genes are able to persist in the population. Finally, white arrows depict whether $\delta \phi / \delta h$ is positive or negative, indicating how more/less HGT changes the population growth rate. 
bioRxiv preprint doi: https://doi.org/10.1101/2020.02.13.947077; this version posted February 16, 2020. The

copyright holder for this preprint (which was not certified by peer review) is the author/funder. All rights

reserved. No reuse allowed without permission.

Starting with the simplest model depicted in Figure 1 $\mathbf{A}$, we first illustrate how the steady-state frequency of carrier cells depends on the benefit of the gene $(b)$ and the rate of HGT $(h)$. Figure 2 A shows that if the gene is sufficiently beneficial, most of the population will consist of carrier cells with or without HGT. Despite being continuously lost, these genes are beneficial enough to readily persist in the population through selection. An increased rate of HGT results in only marginally more carrier cells. For genes with a much smaller benefit, HGT can have a large impact on the frequency of carrier cells in the population. In fact, if the benefit is very small $(b<l$, white dotted line), carriers do not survive in the absence of HGT at all, but can occur in fairly high frequencies with sufficient HGT. Note however that the mere survival of carriers with beneficial genes does not imply a positive impact on the population growth rate, as the model assumes HGT comes at a cost. Actually, at sufficiently high rates of HGT, carrier cells with costly genes $(b<0)$ can also persist in the population, which by definition is deleterious for growth. These costly genes could either be genes that are expressed but not useful in the current environment, or Selfish Genetic Elements (SGEs). Throughout this study, we consider genes with $b<0$ to be SGEs.

\section{Slightly beneficial genes fall into distinct gene classes}

To better understand the impact of HGT, we next study how HGT impacts the population growth rate $(\phi)$. The population growth rate in steady state is given by Equation $\mathbf{1}$ displayed below (see full derivation in Supplementary Section 1). The function is comprised of two parts; one where the population consists only of non-carriers (if $h \leq l-b$ ), and one where carriers survive and the gene persists within the population (if $h>l-b$ ). When the gene persists, an optimal growth rate is found at $h_{\text {opt }}=\sqrt{b l / c}-b$. (see Supplementary Material).

$$
\phi^{*}(h)= \begin{cases}1-c h & \text { if } h \leq(l-b)(\text { gene cannot persist }) \\ 1-c h+b-\frac{b l}{b+h} & \text { if } h>(l-b)(\text { gene persists })\end{cases}
$$

By analysing Equation 1, we find that we can distinguish distinct classes of genes depending on (i) whether HGT is required for the gene to persist within the population, and (ii) whether HGT is beneficial for the population growth rate (Figure 2B). When genes are highly beneficial $(b>l / c)$, HGT is not required for the gene to persist, and HGT does not improve the population growth rate. In other words, although transferring these indispensable genes yields a small increase in the number of carrier cells, this does not outweigh the costs of HGT. When considering lower values of $b$, HGT is still not required for the gene to persist within the population, but transferring these enrichable genes is nevertheless beneficial for population growth rates. For even lower benefit $(b<l)$, HGT is a necessity for the gene to persist within the population, but the population growth rate can be improved by means of intermediate rates of HGT. We call these genes rescuable genes. If we consider genes with even smaller fitness effects $\left(b<4 c l /(1+c)^{2}\right)$, HGT is still required for the survival of these genes, but the population growth rates are highest in the absence of HGT. Thus, despite being defined as a beneficial gene $(b>0)$, transferring these unrescuable genes is not beneficial. Finally, we can consider SGEs, genes with a negative effect on fitness $(b<0)$. These genetic parasites can only persist in the population at very high rates of HGT, but are of course never beneficial for the population growth rate. Figure $2 \mathrm{C}$ shows a bifurcation diagram that summarises how increasing or decreasing rates of HGT impact the population growth rate for these different classes. 
bioRxiv preprint doi: https://doi.org/10.1101/2020.02.13.947077; this version posted February 16, 2020. The copyright holder for this preprint (which was not certified by peer review) is the author/funder. All rights reserved. No reuse allowed without permission.

\section{HGT is an evolutionarily stable strategy, but cannot evolve to 'rescue' rescuable genes}

By analysing the simple model of cells undergoing HGT, we have found 5 distinct gene classes. For two of these classes, namely enrichable and rescuable genes, moderate rates of HGT improve the population growth rates. We next study (i) whether HGT of enrichable and rescuable genes is an evolutionarily stable strategy, and (ii) if bacteria can evolve this strategy de novo. To answer these questions, we consider two competing species: one with that does engage in HGT, and does not $\left(H G T^{+}\right.$and $H G T^{-}$respectively, see Figure $\left.\mathbf{1} \mathbf{B}\right)$. With this model, we have studied the evolution of HGT by means of adaptive dynamics (Metz et al. 1995). If $H G T^{-}$cannot invade $H G T^{+}$, we call HGT an evolutionarily stable strategy, and if $H G T^{+}$can invade $H G T^{-}$we call HGT evolvable.

We found that HGT is an evolutionarily stable strategy for both enrichable and rescuable genes, but that HGT is evolvable only for enrichable genes (see Supplementary Material for full analysis). Even when we assume that the invading $\mathrm{HGT}^{+}$-mutant has the optimal rate of HGT, it cannot invade into a population of $H G T^{-}$cells in steady state. These results were confirmed by numerical analysis, which indeed shows that $H G T^{+}$only invades when the founding population size of $H G T^{+}\left(C^{+} / N^{+}\right)$is relatively large (see Figure $3 \mathbf{A}$ ). This failure to reach the alternative (fitter) evolutionary attractor is caused by positive

frequency-dependent selection (known as the Allee effect). Invading mutants, i.e. a small population of $\mathrm{HGT}^{+}$cells, contain few carrier cells to act as donors for HGT. Moreover, since the resident population of $H G T^{-}$is also not able to retain the rescuable genes, the resident population can also not serve as a donor (see Figure $\mathbf{3 B}$ ). As such, the costs of HGT for an invading $\mathrm{HGT}^{+}$-mutant do not outweigh the potential benefits. In summary, while HGT is an evolutionarily stable strategy, cells cannot evolve HGT to 'rescue' rescuable genes.
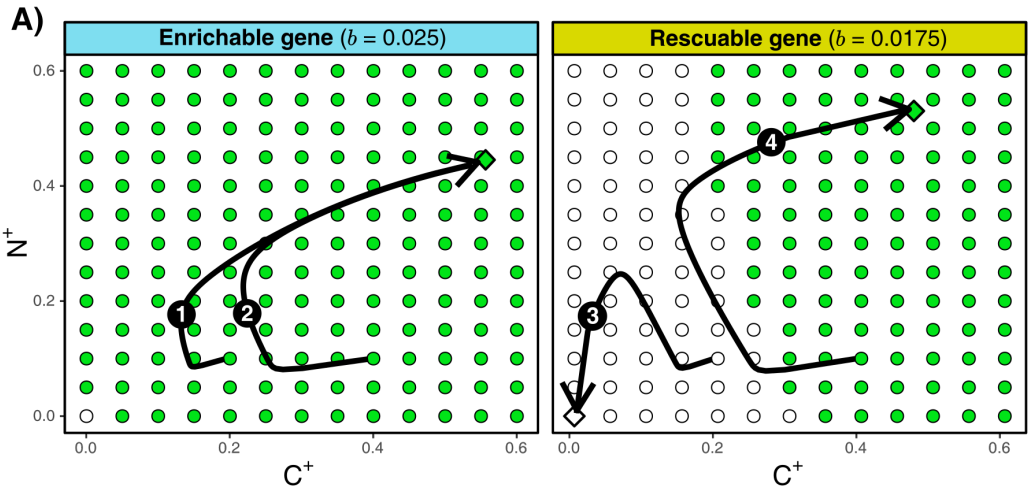

\section{LEGEND \\ Founder population size O $\left[\mathrm{C}^{+}, \mathrm{N}^{+}\right]$(coloured by attractor)}

B)

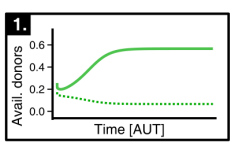

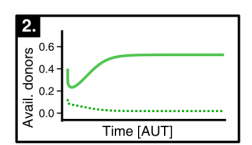
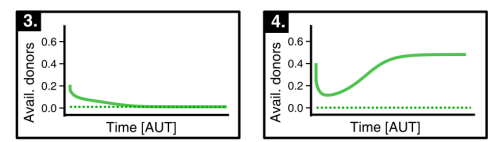

LEGEND

$-\mathrm{C}^{+}$

..... $\mathrm{C}^{-}$

Figure 3: HGT is an evolutionarily stable strategy, but is evolutionarily inaccessible for rescuable genes due to a lack of gene-carrying donor cells. A) For an enrichable and a rescuable gene $(b=0.025$ and $b=0.0175$ respectively), a $2 \mathrm{D}$ projection of the $4 \mathrm{D}$ state space is shown. For various founder sizes (combinations of carriers, $\mathrm{C}^{+}$, and non-carriers, $\mathrm{N}^{+}$), the result of invasion of $\mathrm{HGT}^{+}$(that has the optimal rate of $\mathrm{HGT}$, $\left.h=h_{\text {opt }}\right)$ into $H G T^{-}(h=0)$ is shown. $H G T^{+}$always successfully invades for enrichable genes. For a rescuable gene, low founder populations sizes of $\mathrm{C}^{+}$and $\mathrm{N}^{+}$(white dots) fail to invade, whereas they can invade at higher population sizes (green dots). Black arrows (1-4) show the trajectories starting from two founder population sizes. B) for the four trajectories from A, the graphs show the temporal dynamics of gene-carrying donor cells. 
bioRxiv preprint doi: https://doi.org/10.1101/2020.02.13.947077; this version posted February 16, 2020. The copyright holder for this preprint (which was not certified by peer review) is the author/funder. All rights

\section{Spatial structure hinders the maintenance of genes, making HGT adaptive for a wider range of genes}

So far, we have studied a well-mixed population of cells that undergoes all-against-all competition, and found that HGT is advantageous for slightly beneficial genes that (i) are not too beneficial, as these genes readily persist within the population without HGT, and (ii) are beneficial enough to compensate for the costly HGT. Next, we study the same dynamics of carrier and non-carrier cells in a spatially explicit, eco-evolutionary context. We do this by implementing an individual-based model (IBM), where bacterial cells reside on a grid, interactions are local, and events like HGT and gene loss are implemented as stochastic processes (see Methods and Figure 1 C). When the cells on this grid are sufficiently mixed each time step, the IBM should approximate the dynamics of the ODE model. However, when cellular mixing is minimal, the resulting spatially structured population is more analogous to that of a biofilm. What is the effect of this spatial structure?

A)

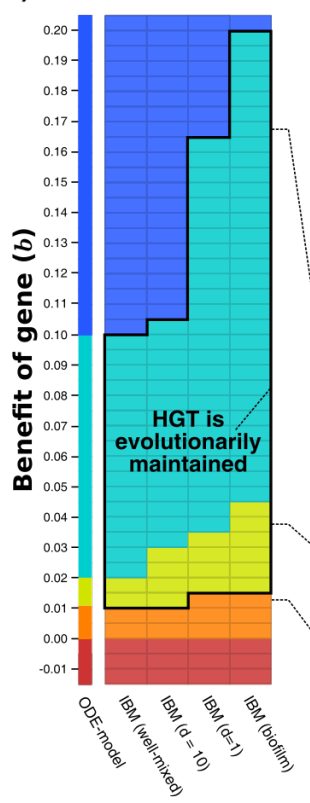

B)
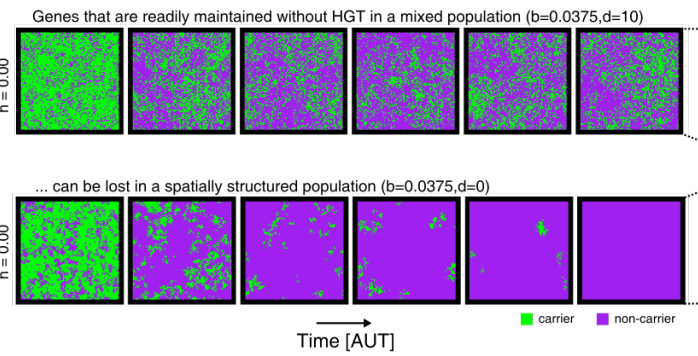

D)
C)

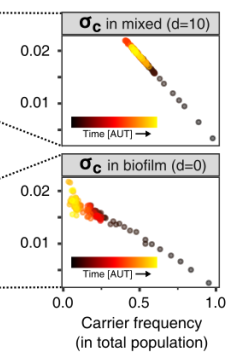

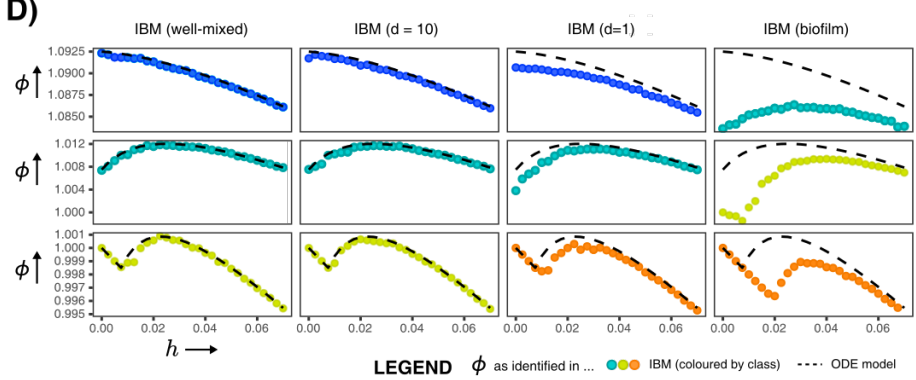

Figure 4: Spatial structure hinders the maintenance of slightly beneficial genes A) Each tile in this table represents a series of simulations in the individual-based model (IBM), where we first test which gene class (background colour) is found when sweeping over different HGT-rates ( $h$-values), and next test whether the observed optimal rate of $\operatorname{HGT}\left(h_{o p t}\right)$ is evolutionarily maintained when starting with a population consisting of only carrier cells (shown with black outline). This was tested for the well-mixed IBM and the IBM with different levels of mixing $(d)$. The continuum of gene classes from the ODE-model is presented for comparison. Colours are the same as in Figure 2 (blue=indispensable, cyan=enrichable, yellow=rescuable, orange $=$ unrescuable, red=selfish genetic element). B) Shown is the spatial grid of the IBM for two simulations with the same value of $b$, and no HGT. The gene readily persists in the mixed IBM (top panel, $d=10$ ), while the gene does not persist in the spatially structured population (bottom panel, $d=0$ ). C) For the simulations shown in $\mathrm{B}$, the average competitive advantage of carrier cells with respect to their local competitors $\left(\sigma_{c}\right.$, see Methods) is plotted against the frequency of carrier cells, showing how clumping hinders the effective benefit of carrying a gene. D) For 3 rows from the table of A, it is illustrated how the effect of spatial clumping illustrated in $\mathrm{B}$ and $\mathrm{C}$ modifies the gene class found for specific $b$-values. The dashed line indicates the growth rates predicted by the ODE model. 
bioRxiv preprint doi: https://doi.org/10.1101/2020.02.13.947077; this version posted February 16, 2020. The copyright holder for this preprint (which was not certified by peer review) is the author/funder. All rights reserved. No reuse allowed without permission.

We first analysed the IBM for a wide variety of values for $b$ and $h$, and measured the average growth rates $\phi$ in the population. We can thus evaluate whether the aforementioned gene classes (indispensable, enrichable, rescuable, unrescuable genes, and SGEs) are found under the same conditions as in the ODE model. Figure 4A shows that, when the IBM is well-mixed, the gene classes indeed occur at values of $b$ identical to the ODE model. However, the gene classes shifts to higher values of $\mathrm{b}$ when mixing is decreased, making the range of benefits which are classified as enrichable and rescuable much broader. In these biofilm populations, HGT was indeed found to be evolutionarily stable for this wider range of fitness-effects (black outline), illustrating that it is not only the value of $b$, but also the ecological context in which a gene finds itself that determines whether or not HGT is adaptive.

What causes these gene classes to shift depending on this spatial context? How does an enrichable gene in the well-mixed system become rescuable in the spatially structured population, as though it is less beneficial? Figure $4 \mathrm{~B}$ shows how this can be intuitively understood by taking into account how individuals in a spatial system mostly compete with their own kind (i.e. progeny and conspecifics). Even when the majority of the population consists of non-carriers, carriers are still competing mostly with other carrier cells. Thus, the effective benefit of carrying the gene is lower in a biofilm, hence the gene becomes harder to maintain within the population. In Figure $4 \mathrm{C}$ is shown that, while carrier cells in the well-mixed populations experience a competitive advantage of $\sim 2 \%$ when carriers make up approximately half the population, carriers in a biofilm only reach a similar competitive advantage at very low carrier frequencies, i.e. when the carriers are almost extinct. At this point, the gene will readily be lost stochastically. The hampered ability of spatially structured population to retain slightly beneficial genes, indeed changes how the population growth rate depends on the rate of HGT (Figure $4 \mathrm{D})$.

\section{HGT evolves for rescuable genes only in a spatially structured population}

The results described in the previous section illustrate that HGT is an evolutionarily stable strategy for a much broader range of $b$-values (fitness effects of genes) in a spatially structured population than in a well-mixed culture. Many more genes are furthermore classified as rescuable in these spatially structured populations, meaning that they can only persist through HGT. We have concluded in the previous section that HGT cannot evolve to 'rescue' these rescuable genes in populations that are well-mixed, fully deterministic, and by only considering a single $\mathrm{HGT}^{+}$mutant type at a time. In the IBM on the other hand, the population is not spatially structured, events are stochastic, and each individual cell has its own rate of HGT. Can these different assumptions help to alleviate the Allee effect mediated by a lack of donor cells, which prevents the evolution of HGT?

To answer the question posed above, we allowed the HGT-rate $(h)$ of all individuals in the IBM to evolve (see Methods). When a non-carrier interacts with a (local) carrier, the $h$-value of this non-carrier (i.e. the acceptor) determines the probability of accepting the gene. For simplicity, we will call individuals with an $h$-parameter greater than $0.02 H G T^{+}$, and the others $H G T^{-}$. We start with a non-carrier population of $H G T^{-}$cells (with $h=0.00$ ), simulate this population for some time (20,000 time steps), and then allow cells to sporadically discover rescuable genes. Since rescuable genes cannot persist without HGT, the fate of this gene depends on the ability of cells to engage in (local) HGT. Using this protocol, we investigate if the rescuable gene is able to spread through the evolution of HGT. We found that HGT never evolved for rescuable genes in well-mixed populations (Figure $\mathbf{5}$ A), consistent with our prior results in the well-mixed ODE model. Thus, we can conclude that the level of stochasticity in the IBM is insufficient to overcome the aforementioned Allee effect caused by a lack of donor cells. 
bioRxiv preprint doi: https://doi.org/10.1101/2020.02.13.947077; this version posted February 16, 2020. The 10

copyright holder for this preprint (which was not certified by peer review) is the author/funder. All rights reserved. No reuse allowed without permission.

In the spatially structured population, HGT of rescuable genes does in fact evolve, therewith 'rescuing' the rescuable genes (Figure 5B). Interestingly however, we found that HGT did not always evolve immediately after the influx of rescuable genes started (yellow arrow), but nevertheless spread steadily once attained. To further elucidate the spread of genes, we barcoded each newly discovered gene with a unique ID, and visualised these on the spatial grid with different colours (Figure $\mathbf{5} \mathbf{C}$ ). Initially, rescuable genes fail to invade, even though different barcodes may locally persist for a while (episode I). After some time however, one gene (green) manages to persist within a local community of transferring cells (episode II). This sets in motion a positive feedback mechanism, where the local abundance of the green gene alleviates the lack of donor cells, transforming nearby $\mathrm{HGT}^{+}$-mutants into carriers, and so on (also see Supplementary Movie). This emergent 'gene-sharing' community eventually overgrows the other cells, and the rescuable gene ultimately persists in up to $\sim 70 \%$ of the population. After the influx of rescuable gene is stopped (episode III), the gene readily persists within the population, showing how this transferring community does not depend on the continuous influx of genes. In summary, HGT of rescuable genes can only evolve if transfer happens within spatially localised sub-populations, and not under well-mixed conditions modelled by mass-action. Through a local 'nucleation event', communities can reach the alternative stable state that can maintain the rescuable gene. Figure 5D summarises the outcome of HGT evolution for a broad range of genes ( $b$-values) with different levels of mixing, revealing how HGT evolves for many more genes in a spatially structured population. Moreover, while HGT of enrichable genes always evolved, HGT only evolved for rescuable genes in spatially structured populations. Finally, as expected from prior results, HGT never evolved for indispensable and unrescuable genes. 
bioRxiv preprint doi: https://doi.org/10.1101/2020.02.13.947077; this version posted February 16, 2020. The copyright holder for this preprint (which was not certified by peer review) is the author/funder. All rights reserved. No reuse allowed without permission.

\section{A) HGT evolution of rescuable gene in well-mixed system}

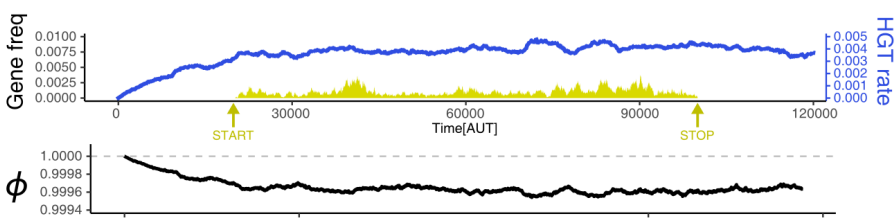

B) HGT evolution of rescuable gene in spatially structured population

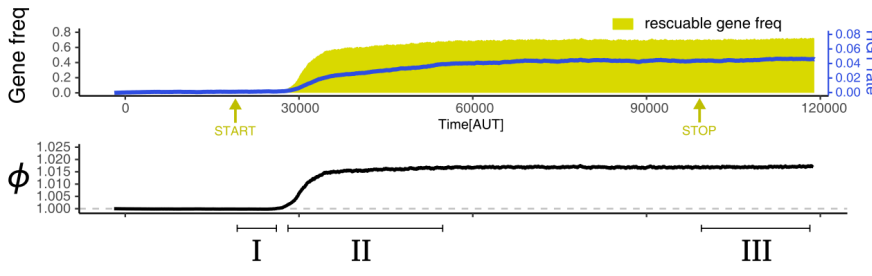

C) HGT evolution in spatial populations is instantiated by local 'nucleation'

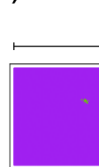

I
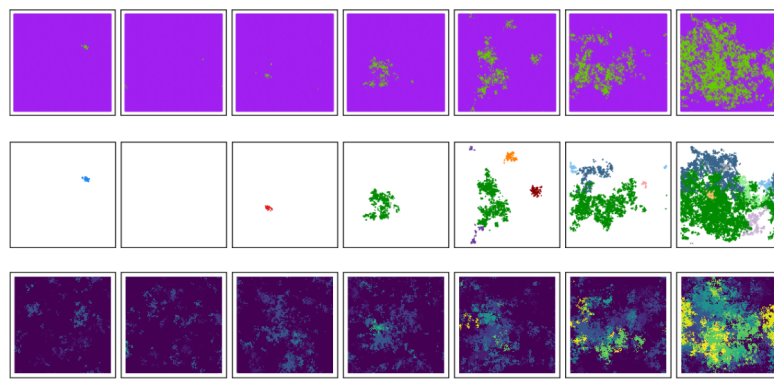

grid columns
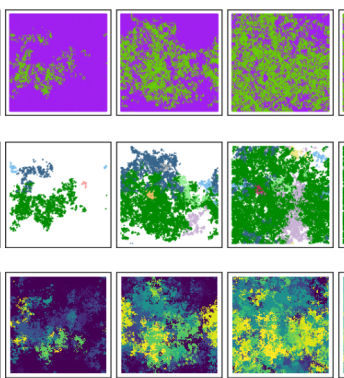

D) HGT evolves for many more genes in spatially structured populations

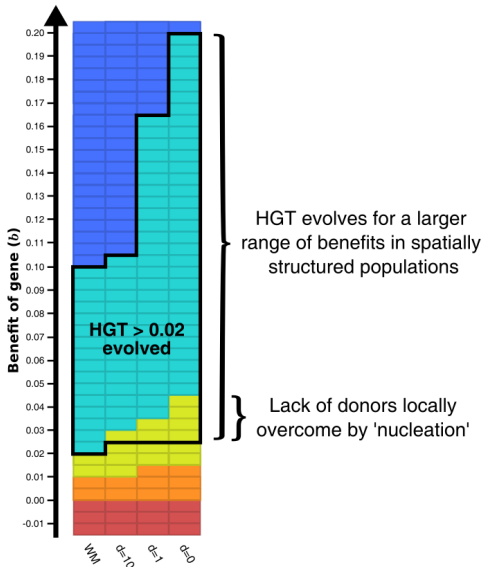

III
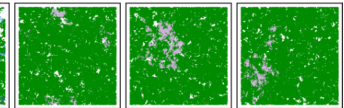

- Genes

(colour-coded

- by barcode)
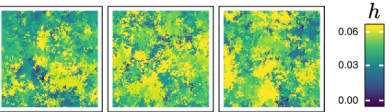

Evolved HGT rate

Figure 5: HGT of rescuable genes only evolves in spatially structured populations due to the emergence of 'gene-sharing' communities: Panel A and B both show the frequency of a rescuable gene (yellow area) that is discovered with a very low probability $\left(5 \cdot 10^{-6}\right.$ per time step), the mean evolved HGT rate of the population (blue line), and the growth rate of the population (black). Note that A and B have a different range in the $\mathrm{y}$-axis for clarity. C shows how in the spatially structured populations, carrier cells with a rescuable gene (colour coded by the unique barcodes) spread after a local 'nucleation event'. A positive feedback loop follows, resulting in a 'gene-sharing' community which slowly overgrows the rest of the population. D shows the outcome of HGT evolution for the same combinations of fitness-effects and mixing as in Figure 4 A. Parameters used: $h_{\text {init }}=0.0, u=5 e-3, m=0.05, l=0.02, c=0.1, f=5 \cdot 10^{-6}, f_{\text {start }}=20.000, f_{\text {stop }}=100.000$, $n=400$ (i.e. $N=400^{2}$ ). For the well-mixed population, we chose a rescuable gene with the highest benefit from Figure $4 \mathbf{A}(b=0.0175)$, and for the spatially structured population we used $b=0.030$ (the average of the much broader range of rescuable genes). Both these genes require HGT to persist, and are thus rescuable within their own spatial context. 
bioRxiv preprint doi: https://doi.org/10.1101/2020.02.13.947077; this version posted February 16, 2020. The copyright holder for this preprint (which was not certified by peer review) is the author/funder. All rights 12

reserved. No reuse allowed without permission.

\section{HGT is evolutionarily maintained in the presence of harmful SGEs}

We have shown that HGT can be adaptive and evolvable for bacteria in order to enrich or rescue slightly beneficial genes. We next investigated if HGT can be maintained under the pressure of harmful SGEs, genetic parasites that spread through horizontal transfer. For this, we consider a population that evolved HGT of a rescuable gene $(b=0.03)$, and expose this population to a low influx of SGEs which confer a fitness penalty $(\beta)$. We study if these SGEs, despite their fitness penalty, can persist within this bacterial population, and if HGT is evolutionarily maintained by the hosts. Figure 6A shows that, when the fitness penalty of the SGEs is small relative to the benefit of the rescuable gene (hereafter called "weak SGEs", $\beta=0.01$ ), these genetic parasites quickly rise to very high frequencies within the population. Although the host cells gradually evolve lower HGT rates in response (from $h \pm 0.05$ it stabilises around $h \pm 0.04$, also see Supplementary Figure $\mathbf{2}$ C), HGT, the rescuable gene, and the SGEs are evolutionarily maintained. When the influx of SGEs is stopped, the cells (and their beneficial gene) stably coexists with these genetic parasites.

Strikingly, if we introduce SGEs whose fitness penalty is greater than the benefit of the gene ("strong SGEs", $\beta=0.04$ ), we also observe the coexistence of cells, rescuable genes, and SGEs. By looking at the initial invasion dynamics (Figure 6B), we can see that these strong SGEs cannot rise to very high frequencies. As the hosts evolve lower rates of HGT, these genetic parasites are pushed to very low frequencies. However, the reduced threat of genetic parasites causes the host cells to once again increase their rates of HGT, leading to a secondary outbreak of SGEs (Figure $\mathbf{6} \mathbf{B}$, from $\mathrm{T}=300,000$ onwards). It is interesting to note that, while the population growth rates $\left(\phi_{p o p}\right)$ clearly decrease due to this second infection, the growth rates along the line-of-descent ( $\phi_{\text {lod }}$, see methods) remains largely unaffected. Thus, while a sub-set of the population has been infected, individuals in this infected strain will not be amongst the long-term ancestors. Counter-intuitively, strong SGEs only have a minor impact on bacterial growth rates, while weaker SGEs impose a significant burden on the population by rising to much higher frequencies (also see Supplementary Figure $\mathbf{5 2}$ C). Finally, stopping the influx of SGEs does not impact the long-term coexistence of cells, beneficial genes, and these strong SGEs (Figure 6C and Supplementary Figure S2 $\mathrm{C}$ ).

To better understand the co-evolutionary process between SGEs and bacteria engaging in HGT of rescuable genes, Figure 6D shows long-term dynamics of barcoded SGEs in this spatial system. Although a diverse set of SGEs are initially discovered in parallel (coloured by their unique barcode), eventually only a single barcode remains after the influx of SGEs is stopped. Moreover, it can also be seen how SGEs are either locally abundant, or entirely absent. Thus, spatially separated strains of bacteria experience opposing selection pressures for HGT. Lower rates of HGT are favoured in the presence of these strong SGEs, but higher rates of HGT are favoured when these genetic parasites have (locally) died out. Indeed, this heterogeneity of SGEs is crucial for the strong SGEs to persist, as well-mixed populations can only retain weaker SGEs (see Supplementary Figure $\mathbf{2}$. Interestingly, we also found that strong SGEs failed to persist when HGT was too localised (e.g. only between neighbouring cells), as the SGEs then could not escape to a new pool of hosts that have high rates of HGT (Supplementary Figure S3. We conclude that, in a spatially structured population, strong SGEs can stably coexist in a bacterial population which maintains HGT to 'rescue' rescuable genes. 
bioRxiv preprint doi: https://doi.org/10.1101/2020.02.13.947077; this version posted February 16, 2020. The copyright holder for this preprint (which was not certified by peer review) is the author/funder. All rights

\section{A) Invasion by weak SGE}
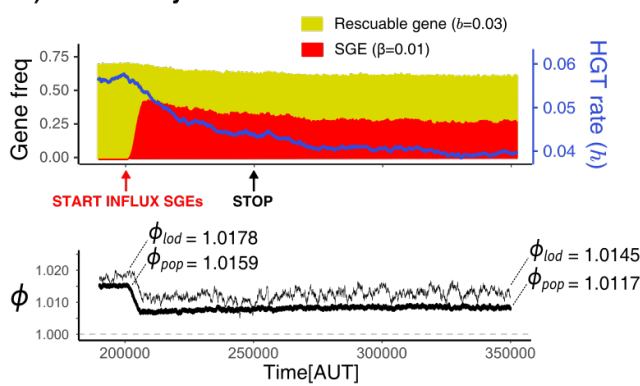

B) Invasion by strong SGE

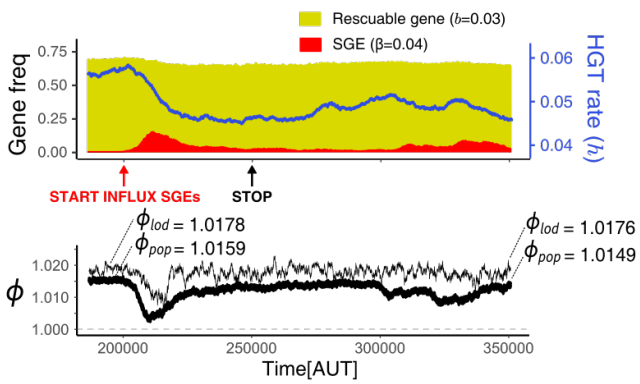

C) Long-term coexistence of cells, beneficial genes, and strong SGEs

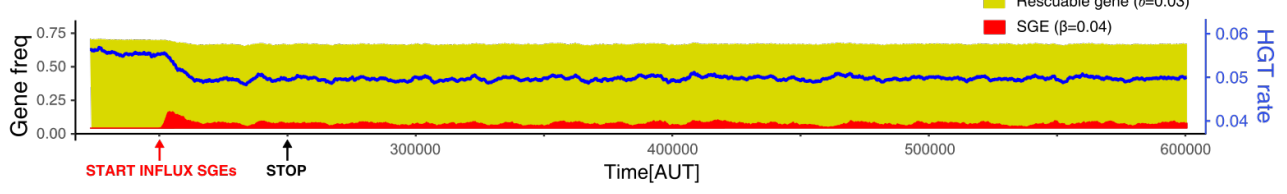

D) Spatial distribution of strong SGEs during initial infection and after prolonged coexistence

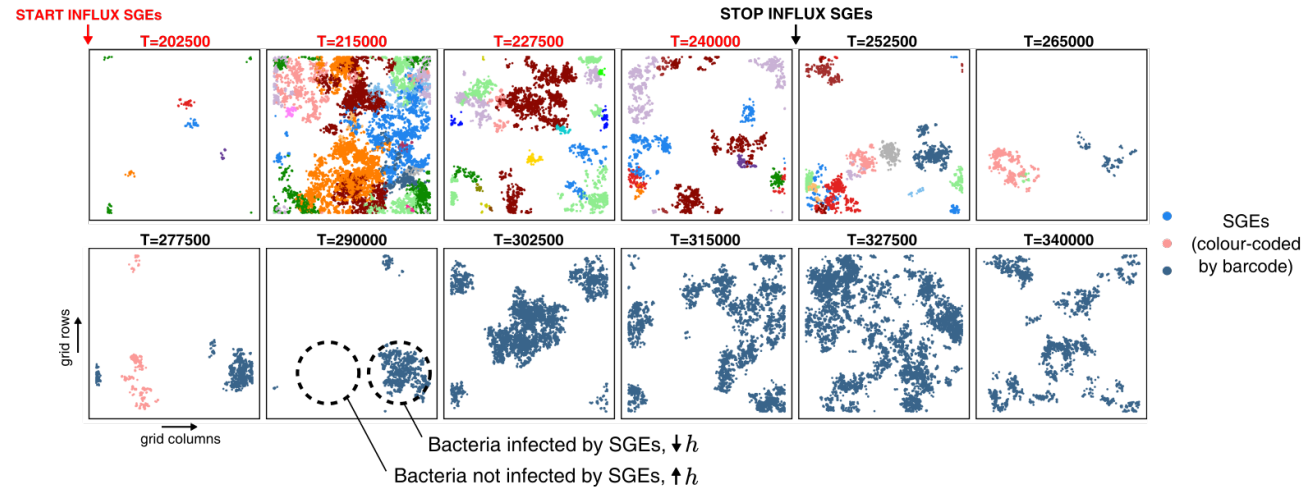

Figure 6: Selfish Genetic Elements (SGEs) can invade and stably coexist with their host cell: A and $\mathrm{B}$ show the temporal dynamics for a population that has evolved to rescue a slightly beneficial gene $(b=0.03)$ invaded by a weak $\operatorname{SGE}(\mathrm{A}, \beta=0.01)$ and a strong $\operatorname{SGE}(\mathrm{B}, \beta=0.04)$ respectively. The blue line indicates the rate of HGT as evolved by the host cells. In the bottom graphs, the thick black line is the average growth rate of the population $\left(\phi_{p o p}\right)$, and the thin black line is $\phi_{l o d}$, the average growth rate along the line of descent (250-1 generations ago). The $\phi_{\text {pop }}$ and $\phi_{l o d}$ that are annotated with the dashed lines are the average of the first/final 200 generations. Panel C shows the long-term coexistence of cells, beneficial genes, and strong SGEs $(\beta=0.04)$. D shows the spatial distribution of SGEs (coloured by their unique barcodes). The top row shows this during the invasion (open ecosystem) and the bottom row shows this during prolonged coexistence (closed ecosystem). Note that the empty sites (white) only indicate the absence of SGEs, not of bacterial cells, which are instead present in every grid point. Parameters used: $h$-parameters and frequency of carriers as evolved from Figure $5=5 e-3, m=0.05, l=0.02, c=0.1, i=1 e-5, i_{\text {start }}=200.000, i_{\text {stop }}=250.000, n=400$ (i.e. $\mathrm{N}=400^{2}$ ). 
bioRxiv preprint doi: https://doi.org/10.1101/2020.02.13.947077; this version posted February 16, 2020. The copyright holder for this preprint (which was not certified by peer review) is the author/funder. All rights 14

reserved. No reuse allowed without permission.

\section{Discussion}

We have studied the balance between the advantages and disadvantages of HGT by modelling transfer of a single gene within a simple bacterial population. Our analysis shows that we can categorise slightly beneficial genes based on whether genes are lost from the population without HGT, and whether HGT of these genes can improve the population growth rate. This results in five distinct gene classes: (i) indispensable genes, that readily persist within the population and for which HGT is therefore always deleterious, (ii) enrichable genes which are not lost from the population without HGT, but moderate rates of HGT are adaptive, (iii) rescuable genes which are lost from the population without HGT, but can be rescued by HGT which improves population growth rates, and (iv) unrescuable genes, that are also lost from the population without HGT, but recovering them with HGT does not improve population growth rates, and (v) selfish genetic elements, genes that confer a fitness penalty, but can persist within the population with HGT. We further investigated if HGT of these genes is an evolutionarily stable strategy, and if HGT of these genes can evolve de novo. We found that horizontal transfer of enrichable and rescuable genes is indeed a evolutionarily stable strategy, but can only evolve from scratch for enrichable genes. The evolution of HGT to 'rescue' a rescuable gene faces a problem under well-mixed conditions: HGT is required for the gene to persist, but sufficient carriers of the gene are necessary to evolve HGT. By modelling this process in a spatially structured population, we show that HGT can nevertheless evolve for these rescuable genes. As carriers of the gene can be locally abundant, emergent communities form that locally retain the gene via HGT, therewith slowly outgrowing other individuals. Finally we show that once stable transferring communities have evolved, selfish genetic elements (SGEs) can stably coexist with the bacterial population and the beneficial genes. In spite of these genetic parasites exploiting the host's ability to transfer, HGT is evolutionarily maintained, providing a doorway to the co-evolutionary process between bacteria and SGEs.

Our model reveals that HGT can be adaptive when considering genes with a fitness benefit that does not sufficiently compensate for the rate of gene loss. While we studied this from the perspective of genes that confer a constant fitness effect (i.e. a constant environment), bacteria in natural microbial ecosystems frequently experience changing selection pressures. For example, some genes confer a large fitness benefit under rare ecological circumstances, e.g. antimicrobial resistance, toxin production, or cooperation (Riley and Wertz, 2002, Cordero et al. 2012, Vogwill and MacLean, 2015, Gerardin et al. 2016, Hehemann et al. 2016, Dimitriu et al. 2019). However, in between such rare opportunities, these traits are not beneficial or even costly. Although these changing selection pressures have been used to explain how certain traits require HGT to persist (Nogueira et al. 2009, Rankin et al., 2011. van Dijk and Hogeweg 2015), our model shows that a similar argument can be made under constant selection pressure, as long as the fitness effect of the genes is small. In other words, our work shows how bacteria may benefit from preferentially mobilising genes that are either constantly, or on average, slightly beneficial.

Besides investigating the impact of HGT for a range of different fitness effects, we have also shown how spatial structure is a key component for the emergence of HGT of rescuable genes. Both conjugation and transformation have indeed been observed to occur more frequently in biofilms than in well-mixed cultures (Madsen et al. 2012), and plasmids have furthermore been shown to be more persistent in biofilms (Stalder et al. [2020). On the other hand, spatial structure can slow down adaptation in asexual populations because individuals are mostly competing with their related conspecifics (Gordo and Campos, 2006, Habets et al. 2007 Chacón and Harcombe 2019). Relatedness has indeed been shown to be an important factor in stabilising HGT, for example of cooperative traits (Mc Ginty et al., 2011). Our model shows that, also without explicitely taking cooperation into account, HGT can only evolve in 
bioRxiv preprint doi: https://doi.org/10.1101/2020.02.13.947077; this version posted February 16, 2020. The copyright holder for this preprint (which was not certified by peer review) is the author/funder. All rights reserved. No reuse allowed without permission.

'gene-sharing' communities which emerge in by local reproduction in spatially structured populations. Thus, not only are relatedness and spatial structure necessarily intertwined, they are crucial for the rare 'nucleation events' that initiates evolution towards increased rates of HGT. Intriguingly, similar nucleation events have been observed in origin of life studies $(\mathrm{Wu}$ and Higgs, 2012) and models of microbial antagonistic interactions (Kotil and Vetsigian, 2018). These types of emergent evolutionary transitions highlight how studying evolution under well-mixed conditions, and one mutant at a time, can be highly misleading. Studying biological systems in a spatial context will help us to better understand which eco-evolutionary outcomes are accessible, and maintainable, by evolution.

\section{Horizontal Gene Transfer: rescue or catastrophe?}

In nature, HGT can happen through a variety of mechanisms that each have their own potential advantages and disadvantages for the host cell (Vogan and Higgs, 2011, Baltrus, 2013). Bacteria do not always have full control over the rates at which HGT happens, especially when considering it as a side-effects of other processes (Redfield, 2001). However, it remains an intriguing question under which specific circumstances bacteria benefit from HGT, whether it is a side-effect or not. By abstracting away from the different mechanisms of HGT, and what it means for a gene to be "beneficial", we have revealed the conditions under which HGT is an adaptive trait for the host cells. In a similar spirit, earlier modelling by Vogan \& Higgs has shown that HGT can be adaptive with respect to genes that are frequently lost Vogan and Higgs, 2011). However, in their work, natural selection eventually favoured improved replication accuracy, therewith decreasing the advantage of HGT. Other models have shown that HGT is beneficial to mitigate the effects of Mullers Rachet (Muller 1964) by decreasing assortment load (Takeuchi et al. 2014, Vig-Milkovics et al., 2019), analogous to the impact of sex and recombination on the balance between drift and selection (Lynch et al. 1995 Schultz and Lynch, 1997, Lynch et al. 2016, Vos et al., 2019). Our work complements these aforementioned studies by showing that, however low the rate of gene loss may be, there may always be a class of slightly beneficial traits for which HGT is adaptive and evolvable. Although genes with such small fitness effects are very hard to detect experimentally Bataillon, 2000, Wiser and Lenski 2015), our model is a proof of principle that HGT may play a key role in preventing the loss of these genes, which may explain the differential rates of HGT as observed in the data (Nogueira et al. 2009 Rankin et al. 2011, Madsen et al. 2012, Novick and Doolittle, 2020). With the upswing and improvement of experimental techniques like Hi-C metagenomics (Beitel et al. 2014. Burton et al. 2014) and DNA barcoding (Blundell and Levy 2014. Ba et al. 2019), we will soon have more insights into the eco-evolutionary dynamics of small-effect mutations (Li et al. 2018, Lerner et al. 2019) and accessory genes (Quistad et al. 2019. Yaffe and Relman 2020), and we may learn when HGT can come to rescue a microbial population, and when it may be nothing more than a catastrophe. 
bioRxiv preprint doi: https://doi.org/10.1101/2020.02.13.947077; this version posted February 16, 2020. The copyright holder for this preprint (which was not certified by peer review) is the author/funder. All rights 16

reserved. No reuse allowed without permission.

\section{Materials and Methods}

\section{General overview}

In this work, we study the dynamics of bacteria undergoing HGT of slightly beneficial genes and Selfish Genetic Elements (SGEs). We do this by modelling the same processes with gradually increasing complexity, starting from simple Ordinary Differential Equations (ODEs), and then evaluating the same dynamics in an Invididual-based Model (IBM). A graphical representation of these models is found in the main text (Figure 1). The models consider the competition between cells of two types: carrier cells $(C)$ that carry a gene, and non-carrier cells $(N)$. When carrier cells contain a beneficial gene (i.e. it is a beneficial trait), they grow faster than the non-carrier cells $(N)$. However, carriers may lose this beneficial gene with a fixed rate $l$. Both cell types engage in HGT with rate $h$, which comes with a cost $c$. This cost is equal for both cell types, meaning that whatever the costs may entail, we assume they are continuously payed. Proportional to the density of available carrier cells, non-carriers can be transformed back into a carrier cell by means of "additive" HGT. Both models use a chemostat assumption, where cells wash out at a rate proportional to the rate of growth, ensuring a constant population size in steady state.

\section{ODE model(s)}

By modeling the dynamics described above by means of ODEs, we assume a well-mixed population of cells that compete according to all-against-all dynamics (i.e. mass-action). Our equations describing the density of carrier $(C)$ and non-carrier $(N)$ cells are given in Equation 2. where $b$ is the benefit of the carried gene (or burden if $b<0$ ), $l$ is the rate of gene loss, $h$ is the rate at which cells engage in HGT, $c$ is the continuous cost for engaging in HGT, and HGT transforms a non-carrier into a carrier when they interact $(h C N)$. This cost for HGT $(c)$ is equal for both cell types, meaning that whatever the costs may entail, we assume they are continuously payed. Finally, the total amount of growth $(\phi)$ is subtracted from both populations, meaning that the population density in steady state is always 1 .

$$
\begin{aligned}
\frac{\mathrm{d} C}{\mathrm{~d} t} & =\underbrace{(1-c h+b) C}_{\text {reproduction of } \mathrm{C}}-\underbrace{l C}_{\text {gene loss }}+\underbrace{h C N}_{\mathrm{HGT}}-\underbrace{\phi C}_{\text {chemostat }} \\
\frac{\mathrm{d} N}{\mathrm{~d} t} & =\underbrace{(1-c h) N}_{\text {reproduction of } \mathrm{N}}+\underbrace{l C}_{\text {gene loss }}-\underbrace{h C N}_{\mathrm{HGT}}-\underbrace{\phi N}_{\text {chemostat }} \\
\phi & =\underbrace{(1-c h+b) C}_{\text {total growth of } \mathrm{C}}+\underbrace{(1-c h) N}_{\text {total growth of } \mathrm{N}} \\
C+N & =1 \text { (constant population size, ensured by chemostat assumption.) }
\end{aligned}
$$

From the above model, we derived how the population growth rate $(\phi)$ depends on both $b$ and $h$ (see Equation 1 in the main text), which shows the conditions under which HGT improves the total growth rate of the population. To analyse whether or not HGT could evolve, we extended the two-variable ODE model above (of cells with the same $h$ ) to a four-variable ODE model (of two species with a different $h$, see Figure 10 and Equation 3 below). We use this extension to study whether or not a species with $\mathrm{HGT}\left(C^{+}\right.$and $\left.N^{+}, h>0\right)$ could invade upon a species without HGT $\left(C^{-}\right.$and $N^{-}, h=0$ ), and vice versa (see Supplementary material for full analysis). Finally, we also extended the ODE model to study the impact on growth rates for cells that engage in HGT of both a beneficial gene and a Selfish Genetic Element (SGE), which can be found in the Supplementary Material. 
bioRxiv preprint doi: https://doi.org/10.1101/2020.02.13.947077; this version posted February 16, 2020. The copyright holder for this preprint (which was not certified by peer review) is the author/funder. All rights reserved. No reuse allowed without permission.

$$
\begin{aligned}
\frac{\mathrm{d} C^{-}}{\mathrm{d} t} & =(1+b) C^{-}-l C^{-}-\phi C^{-} \\
\frac{\mathrm{d} N^{-}}{\mathrm{d} t} & =N^{-}+l C^{-}-\phi N^{-} \\
\frac{\mathrm{d} C^{+}}{\mathrm{d} t} & =(1+b-c h) C^{+}-l C^{+}+h N^{+}\left(C^{-}+C^{+}\right)-\phi C^{+} \\
\frac{\mathrm{d} N^{+}}{\mathrm{d} t} & =(1-c h) N^{+}+l C^{+}-h N^{+}\left(C^{-}+C^{+}\right)-\phi N^{+} \\
\phi & =(1+b) C^{-}+N^{-}+(1+b-c h) C^{+}+(1-c h) N^{+}
\end{aligned}
$$

\section{Individual-based model}

The individual-based model (IBM) describes the same dynamics as the ODE models, but differs in some important aspects. Firstly, individuals are discrete entities that live on a 2D grid, and reproduce locally. This allows us to study the model with and without spatial pattern formation by modifying the rate at which cells mix. When mixing is disabled or very limited, a spatially structured population like that of a biofilm will form, while an increased amount of cellular mixing will approximate a well-mixed culture. Under well-mixed conditions, individuals will interact with random individuals in the population (approximating the all-against-all dynamics of the ODEs), while individuals will interact mostly with their conspecifics in case of the biofilm. We explicitly define a competition range (focal cell plus its 8 neighbouring grid points) and a HGT range (all cells within distance $t$ ) which determine smaller samples of the total population with which individuals can interact. Each individual (potentially) has its own $h$-parameter, allowing us to study the evolution of HGT in an eco-evolutionary context (see implementation of mutations below). As we primarily focus on the question if cells benefit from taking up genes from their environment or other cells, we assume that the $h$-parameter of the acceptor cell determines the probability of HGT. The IBM also includes a low rate $(f)$ at which genes with benefit $b^{*}$ are (re)discovered, allowing us to study how and if newly discovered genes / selfish elements spread through the population. Finally, note that processes such as gene loss, HGT, and competition are no longer deterministic like in the ODEs, but implemented as events that can stochastically happen at each simulated time step. To ensure the chance-events in the IBM (reproduction, HGT, gene loss) accurately represent the rates as used in the ODE, all probabilities were multiplied by a small constant $\Delta \mathrm{T}=0.1$.

Updating grid points: All grid points $i, j$ in the IBM contain a single cell which can be a carrier or non-carrier $\left(b_{i, j}=b\right.$ for carriers, $b_{i, j}=0$ for non-carrier $)$, which can carry a SGE $\left(\beta_{i, j}=\beta\right.$ for SGE infected cells, $\beta_{i, j}=0$ for uninfected cells), and have an individual HGT-parameter $h_{i, j}$. At each time step, local reproduction happens in each grid point $i, j$ by drawing a random individual from the Moore (9 cells) neighbourhood and letting it reproduce with a probability proportional to its growth-rate $\varphi_{i, j}$ :

$$
\varphi_{i, j}=1+b_{i, j}-\beta_{i, j}-c h_{i, j}
$$

When reproduction happens, the winner cell replicates and replaces the cell in grid point $i, j$. This newborn cell is an exact copy of the mother cell. Next, all cells are also updated to include the processes of stochastic gene loss with rate $l$, HGT with rate $h_{i, j}$, and gene/SGE discoveries based on the influx-rate $f$. Finally, with a small probability $u$, the HGT rate of any individual can mutate, where a cell uniformly samples a new parameter between $h_{i, j}-m$ and $h_{i, j}+m$. 
bioRxiv preprint doi: https://doi.org/10.1101/2020.02.13.947077; this version posted February 16, 2020. The copyright holder for this preprint (which was not certified by peer review) is the author/funder. All rights 18

reserved. No reuse allowed without permission.

IBM growth rates: With respect to growth rates, the simulated IBM model does not only track the average growth rate of all cells in the population $\left(\phi_{p o p}\right)$, but also tracks the growth rate of the line of descent that gave rise to the current population $\left(\phi_{\text {lod }}\right)$. While $\phi_{\text {pop }}$ is comparable to $\phi$ in the ODE-model, $\phi_{\text {lod }}$ gives us insights into how the long-term ancestors are impacted by HGT. We also measure the competitive advantage that carrier cells have over non-carriers when competing (locally) for reproduction $\left(\sigma_{c}\right)$, which is defined as the average fitness advantage a carrier has over its local competitors ( 8 neighbouring sites). When all competitors of a carrier are carriers, $\sigma_{c}$ approaches 0 . When all competitors are non-carriers, $\sigma_{c}$ approaches $b$.

IBM barcoding: We tag all influxed genes and SGEs with a unique identifier, allowing us to visualise how genes / SGEs spread through the population (analogous do DNA barcoding (Blundell and Levy, 2014 Levy et al. 2015, Ba et al. 2019, Lerner et al. 2019)). These barcodes also allow us to investigate whether or not these genes are continuously rediscovered, or form long lineages of genes that persist within the population.

\section{Parameters used:}

Throughout most of this study, the gene loss $l$ was set to 0.02 and the cost for HGT was set to $c=0.2$. In general, our results do not depend on the precise value of these two parameters. For example, when the rate of gene loss is set to much lower (arguably more realistic) values, the gene classes discussed in Figure 2 simply shift to lower values of $b$. Similarly, if the costs are higher, the parameter-region where HGT is adaptive for the host cells (i.e. enrichable and rescuable genes) is more narrow, but is still retained. Parameters such as the benefit $(b)$, the HGT-rate $(h)$, the amount of mixing $(d)$, and the HGT distance $(t)$ have been extensively sweeped, as discussed in the main text / Supplementary Material. In these cases, the used parameters are given in the captions of the relevant figures. When comparing the IBM with the ODE models (e.g. occurrence of gene classes), evolution of $h$ was disabled $(u=0.0)$. For the de novo evolution of HGT, the initial population consisted only of non-carrier cells, but genes fluxed in at a low rate $(f=5 \cdot 10 e-6)$, while the initial level of $\operatorname{HGT}(h=0.0)$ was allowed to evolve with $u=5 \cdot 10 e-5$ with a uniform step size of $m=0.05$. Finally, when testing whether HGT could be maintained, no influx of genes was present $(f=0.0)$, but the initial population consisted of carrier-cells that, at least initially, all have the optimal rate of hgt $\left(h=h_{\text {opt }}\right.$, see supplementary material). All experiments in the IBM with Selfish Genetic Elements were done with slightly lower costs $(c=0.1)$, to compensate for the extra costs imposed by these genetic parasites.

All the important parameters of our models are summarised in Table $\mathbf{1}$

\section{Software used}

The analytical model was numerically analysed using grind.R by R.J. de Boer (http://tbb.bio.uu.nl/rdb), a R script that uses the deSolve R-package (Soetaert et al. 2010). The simulated model was implemented in Cash (Cellular Automaton simulated hardware) version 2.1, an free and easy-to-use library to make simple spatially explicit simulations (originally created by R.J. de Boer \& A.D. Staritsk, further developed by Nobuto Takeuchi and Bram van Dijk). Visualisation of both models was done in $\mathrm{R}$ using ggplot Wickham 2016) and plotly (Inc. 2015). Simulations were run in Linux Ubuntu 16.04 LTS using GNU parallel(Job).

Both the R-scripts for ODE analysis and the IBM code implemented in C, are available online https://github.com/bramvandijk88/HGT_Genes_And_SGEs 
Table 1: Description of parameters used in the models

Gene loss $(l)$

HGT rate $(h)$

Benefit of gene $(b)$

Costs of HGT (c)
Rate at which carrier cells lose the beneficial gene

Rate at which non-carriers are transformed into carriers (when interacting with carrier cells)

Growth rate benefit for carrier cells (or penalty for negative b)

Growth rate penalty for the rate of HGT

Parameter (IBM only)

\section{Description}

Grid size $(n)$

Mixing rate $(d)$

Competition range $(s)$

HGT distance $(t)$

Influx genes $(f)$

Benefit of influxed gene $(b *)$

Influx SGEs $(i)$

Fitness penalty of SGE $(\beta)$

Mutation rate $(\mu)$

Mutation step $(m)$
The simulation is done on a square grid of $\mathrm{n} \times \mathrm{n}$ cells

Every time step, the grid is mixed $d$ times using the Margolus Diffusion algorithm (Toffoli and Margolus, 1987). Alternatively, the population was well-mıxed by assigning new positions at random every time step.

Sub-population of $\mathrm{s} x \mathrm{~s}$ cells surrounding focal grid point that compete for reproduction

Sub-population of $\mathrm{d} x \mathrm{~d}$ cells surrounding focal grid point from which a random potential donor is sampled for HGT

A small probability for any cell to discover a gene de novo

Growth rate benefit for carrier cells (or penalty for negative b)

A small probability for any cell to be infected by an SGE de novo de novo

The fitness penalty imposed by the SGE

Chance of mutating the evolvable HGT-rate

Uniform step size of mutations 
bioRxiv preprint doi: https://doi.org/10.1101/2020.02.13.947077; this version posted February 16, 2020. The copyright holder for this preprint (which was not certified by peer review) is the author/funder. All rights 20 reserved. No reuse allowed without permission.

\section{Acknowledgements}

This work was supported by the European Commission 7th Framework Programme (FPFP7-ICT-2013.9.6 FET Proactive: Evolving Living Technologies) EvoEvo project (ICT-610427). 
bioRxiv preprint doi: https://doi.org/10.1101/2020.02.13.947077; this version posted February 16, 2020. The copyright holder for this preprint (which was not certified by peer review) is the author/funder. All rights reserved. No reuse allowed without permission.

\section{Supplementary Material}

This supplementary material includes the mathematical derivations of the results discussed in the main text and some extra insights and figures. The source code material to reproduce the numerical simulations we have done (both in the main text and in this supplementary material), is available online (https://github.com/bramvandijk88/HGT_Genes_And_SGEs).

\section{Part I: Mathematical analyses}

\section{Equilibria and population growth rate of a single population}

As described in the main text, we consider a population of cells that either carry or do not carry a gene. The dynamics of the density of carriers $(C)$ and non-carriers $(N)$ are described by:

$$
\begin{aligned}
\frac{\mathrm{d} C}{\mathrm{~d} t} & =\underbrace{(1-c h+b) C}_{\text {reproduction of } \mathrm{C}}-\underbrace{l C}_{\text {gene loss }}+\underbrace{h C N}_{\text {HGT }}-\underbrace{\phi C}_{\text {chemostat }} \\
\frac{\mathrm{d} N}{\mathrm{~d} t} & =\underbrace{(1-c h) N}_{\text {reproduction of } \mathrm{N}}+\underbrace{l C}_{\text {gene loss }}-\underbrace{h C N}_{\mathrm{HGT}}-\underbrace{\phi N}_{\text {chemostat }} \\
\phi & =\underbrace{(1-c h+b) C}_{\text {total growth of } \mathrm{C}}+\underbrace{(1-c h) N}_{\text {total growth of } \mathrm{N}} \\
C+N & =1 \text { (constant population size, ensured by chemostat assumption.) }
\end{aligned}
$$

\section{Equilibria and their stability}

The equilibria of Eq 58 are found by solving $\frac{\mathrm{d} C}{\mathrm{~d} t}=\frac{\mathrm{d} N}{\mathrm{~d} t}=0$.

$$
\text { Let } \frac{\mathrm{d} C}{\mathrm{~d} t}=(1+b+c h) C-l C+h N C-\phi C=0 .
$$

Then either $C=0$,

or $\phi=1+b-c h-l+h N$ and

$$
\begin{aligned}
& 1+b-c h-l+h N=(1+b-c h) C+(1-c h) N \\
\Longleftrightarrow & 1+b-c h-l+h(1-C)=(1+b-c h) C+(1-c h)(1-C) \\
\Longleftrightarrow & 1+b-c h-l+h=(1+b-c h+h-1+c h) C+1-c h \\
\Longleftrightarrow & b-l+h=(b+h) C \\
\Longleftrightarrow & C=\frac{b-l+h}{b+h}=1-\frac{l}{b+h}
\end{aligned}
$$

Using $C+N=1$, we find that the system has two equilibria:

$$
\begin{array}{ll}
\text { equilibrium (i): } & C^{*}=0, \quad N^{*}=1, \\
\text { equilibrium (ii): } & C^{*}=1-\frac{l}{b+h}, \quad N^{*}=\frac{l}{b+h}
\end{array}
$$

Next, we study under what conditions the gene can persist in the population described by $\mathrm{Eq} 58$. Note that this is equivalent to asking when equilibrium (i) is unstable, i.e., when the carrying cells $(C)$ can invade on a resident population of non-carrying cells $(N)$ at carrying capacity. When the system is in equilibrium (i), $C^{*}=0, N^{*}=1$, and $\phi^{*}=(1-c h)$. The dynamics of the carrying cells can then be approximated by

$$
\frac{\mathrm{d} C}{\mathrm{~d} t} \approx\left(1+b-c h-l+h N^{*}-\phi^{*}\right) C=(1+b-c h-l+h-(1-c h)) C=(b+h-l) C,
$$


bioRxiv preprint doi: https://doi.org/10.1101/2020.02.13.947077; this version posted February 16, 2020. The 22

copyright holder for this preprint (which was not certified by peer review) is the author/funder. All rights reserved. No reuse allowed without permission.

and the carrying cells can invade iff $\frac{\mathrm{d} C}{\mathrm{~d} t}>0$, i.e., iff

$$
b+h-l>0 \text {. }
$$

From Eq11 we can conclude that genes which yield a sufficient growth rate benefit to overcome the loss rate $(b>l)$ do not need HGT in order to persist in a population. Slightly beneficial genes, however, only persist when $h>(l-b)$. HGT, serving as a plausible "back-mutation", prevents the eventual loss of such a gene from the population.

\section{Population growth rate $\phi$ in steady state as a function of HGT rate $h$}

Even though we have shown above that some genes can only persist in a population at sufficiently high rates of HGT, the survival of these genes does not necessarily imply that HGT also improves the actual growth rate of the population under these conditions, as the model also assumes a cost for higher rates of HGT. To gain better insight into when HGT improves the steady state growth rate, we will next consider how the population growth rate $\phi$ depends on $h$. The population growth rate in steady state, $\phi^{*}$, is given by:

$$
\begin{aligned}
\phi^{*}(h) & =(1+b-c h) C^{*}+(1-c h) N^{*} \\
& = \begin{cases}1-c h & \text { if } h \leq(l-b) \text { (gene cannot persist) } \\
1-c h+b-\frac{b l}{b+h} & \text { if } h>(l-b) \text { (gene persists) }\end{cases}
\end{aligned}
$$

To determine the effect of the rate of HGT, $h$, on the steady state population growth rate $\phi^{*}$, we differentiate $\mathrm{Eq} 13$ with respect to $h$ :

$$
\frac{\partial \phi^{*}}{\partial h}= \begin{cases}-c & \text { if } h \leq(l-b) \\ -c+\frac{b l}{(b+h)^{2}} & \text { if } h>(l-b) .\end{cases}
$$

As long as $h<(l-b), \frac{\partial \phi^{*}}{\partial h}=-c<0$ and an increase in HGT rate $h$ will decrease the population growth rate at steady state $\phi^{*}(h)$. For, $h>(l-b)$, the population growth rate $\phi^{*}$ might however have a local optimum, which we can find by setting $\frac{\partial \phi^{*}}{\partial h}$ to 0 :

$$
\begin{aligned}
& \frac{b l}{(b+h)^{2}}-c=0 \\
& \Longleftrightarrow(b+h)^{2}=\frac{b l}{c}
\end{aligned}
$$

from which we can solve

$$
h_{\mathrm{opt}}=\sqrt{\frac{b l}{c}}-b
$$

Note that this optimum is only obtained in the function $\phi^{*}(h)$ if $h_{\mathrm{opt}}>(l-b)$ :

$$
\begin{aligned}
& \sqrt{\frac{b l}{c}}-b>l-b \\
& \Longleftrightarrow \frac{b l}{c}>l^{2} \\
& \Longleftrightarrow b>l c .
\end{aligned}
$$

(This is the same condition found when solving $\frac{\partial \phi^{*}}{\partial h}>0$ at $h=(l-b)$ ) 
bioRxiv preprint doi: https://doi.org/10.1101/2020.02.13.947077; this version posted February 16, 2020. The

copyright holder for this preprint (which was not certified by peer review) is the author/funder. All rights

reserved. No reuse allowed without permission.

Furthermore, since $h$ is the rate of HGT, we are only interested in positive values of $h . h_{\text {opt }}>0$ iff

$$
\begin{aligned}
\sqrt{\frac{b l}{c}} & >b \\
b & <\frac{l}{c} .
\end{aligned}
$$

Under the conditions of $\mathrm{Eq} 18$ and 20 the second derivative of $\phi^{*}$ to $h$ is

$$
\frac{\partial^{2} \phi^{*}}{\partial h^{2}}=\frac{-2 b l}{(b+h)^{3}}
$$

which is negative if the parameters $b$ and $l$ are $\geq 0$. Hence, when $\phi^{*}(h)$ has an optimum for a positive HGT rate $h_{\mathrm{opt}}$, this local optimum is a maximum. The growth rate in this local maximum is larger than the growth rate at $h=0, \phi^{*}(0)=1$, iff

$$
\begin{aligned}
\phi^{*}\left(h_{\mathrm{opt}}\right)=1-c h_{\mathrm{opt}}+b-\frac{b l}{b+h_{\mathrm{opt}}}>1 \\
\Longleftrightarrow 1+c b-\sqrt{b c l}+b-\frac{b l}{\sqrt{\frac{b l}{c}}}>1 \\
\Longleftrightarrow b(1+c)-2 \sqrt{b c l}>0 \\
\Longleftrightarrow b>\frac{4 l c}{(1+c)^{2}} .
\end{aligned}
$$

Summarising, the population growth rate at equilibrium, $\phi^{*}$, decreases linearly with the risks $c h$ when $h<(l-b)$ due to the costs of HGT (see Eq 13). Under these conditions, the growth rate does not depend on $b$ because the gene cannot persist in the population. When $h>(l-b)$, the gene does persist within the population, resulting in an extra term $b-\frac{b l}{b+h}$ in the growth rate $\phi^{*}(h)$. This extra term approaches a maximal benefit of $b$ for high values of $h$. The burden of HGT ch will however eventually outweigh this benefit for increasing rates of HGT. A (local) optimal rate of HGT can found at $h_{\mathrm{opt}}=\sqrt{b l / c}-b$, as long as $b>l c$. This optimal HGT rate is greater than 1, meaning that HGT improves the population growth rate at steady state, if the genes have a minimal benefit (see Eq 24). However, when the benefit is too large $(b>l / c)$, the optimal HGT rate becomes $h_{\mathrm{opt}}<0$. As negative values for HGT are biologically unsound, HGT never improves the population growth rate in steady state for genes with such a high fitness benefit. Following these derivations, genes can be divided in different classes based on the value of the fitness benefit $b$ and the consequent effect of HGT on the population growth rate at steady state (see main text and Figure 2):

Selfish Genetic Elements (SGEs) $(b<0)$ Carrying the gene confers a fitness cost. Increasing HGT-rates only lower the equilibrium population growth rate $\phi^{*}$.

Unrescuable genes $\left(b<l\right.$ and $\left.b<\frac{4 l c}{(1+c)^{2}}\right)$ Genes confer a small fitness benefit, but this benefit is too small to overcome gene loss. Furthermore, no positive HGT rate $h$ improves the population growth rate $\phi^{*}(h)$ over the population growth rate in the absence of HGT $\left(\phi^{*}(0)=1\right)$.

Rescuable genes $\left(\frac{4 l c}{(1+c)^{2}}<b<l\right)$ Genes confer a small fitness benefit and cannot persist in a population in the absence of HGT, but can be rescued by a sufficiently high HGT rate $(h>(l-b))$. For some HGT rate $h_{\mathrm{opt}}>0$ the equilibrium growth rate $\phi^{*}(h)>1$, indicating that HGT can improve the growth rate of the population. 
bioRxiv preprint doi: https://doi.org/10.1101/2020.02.13.947077; this version posted February 16, 2020. The 24 reserved. No reuse allowed without permission.

Enrichable genes $(l<b<l / c)$ Genes confer a sufficient fitness benefit to persist in a population in the absence of HGT. HGT can however improve the equilibrium population growth rate $\phi^{*}\left(h_{\mathrm{opt}}\right)$.

Indispensable genes $(b>l / c)$ Genes confer a large fitness benefit and can persist in a population in the absence of HGT. HGT furthermore does not improve the equilibrium population growth rate. 
bioRxiv preprint doi: https://doi.org/10.1101/2020.02.13.947077; this version posted February 16, 2020. The copyright holder for this preprint (which was not certified by peer review) is the author/funder. All rights reserved. No reuse allowed without permission.

\section{Evolutionary stability of $H G T^{+}$and $H G T^{-}$populations}

To study whether HGT is an evolvable trait, we will consider 1) if HGT can evolve de novo, and 2) if HGT can be evolutionarily maintained. For this, we extended the two-variable model of one species to a four-variable model of two species: a $\mathrm{HGT}^{+}$-species that engages in $\mathrm{HGT}$, and $\mathrm{HGT}^{-}$-species that does not (Supplementary Figure $\mathrm{S} \mathbf{1 B}$, Equation 25, 28). We analysed under what conditions the $\mathrm{HGT}^{+}$-species can invade an equilibrium of the $\mathrm{HGT}^{-}$-species, and vice versa. We found that HGT can only evolve for an enrichable gene, but is evolutionarily maintained for both enrichable and rescuable genes. The following paragraphs will elaborate on how these results are derived:

Consider a $\mathrm{HGT}^{+}$-species $\left(C^{+}, N^{+}\right)$and a $\mathrm{HGT}^{-}$-species $\left(C^{-}, N^{-}\right)$that differ in their HGT rate $h$, but are identical otherwise. The dynamics of the density of cells carrying and not carrying the gene of the two species can be described by the following equations:

$$
\begin{aligned}
\frac{\mathrm{d} C^{-}}{\mathrm{d} t} & =(1+b) C^{-}-l C^{-}-\phi C^{-} \\
\frac{\mathrm{d} N^{-}}{\mathrm{d} t} & =N^{-}+l C^{-}-\phi N^{-} \\
\frac{\mathrm{d} C^{+}}{\mathrm{d} t} & =(1+b-c h) C^{+}-l C^{+}+h N^{+}\left(C^{-}+C^{+}\right)-\phi C^{+} \\
\frac{\mathrm{d} N^{+}}{\mathrm{d} t} & =(1-c h) N^{+}+l C^{+}-h N^{+}\left(C^{-}+C^{+}\right)-\phi N^{+} \\
\phi & =(1+b) C^{-}+N^{-}+(1+b-c h) C^{+}+(1-c h) N^{+} \\
C^{-}+N^{-}+C^{+}+N^{+} & =1 .
\end{aligned}
$$

Note that we include horizontal gene transfer from $\mathrm{HGT}^{-}$-cells carrying the gene to $\mathrm{HGT}^{+}$-cells that do not yet carry the gene. In other words, we consider a situation in which the propensity of HGT is determined by the acceptor cell, and not by the donor. This is inspired by for instance the process of transformation, in which the acceptor cell "decides" whether or not it takes up extracellular DNA.

If HGT is evolvable de novo, the $\mathrm{HGT}^{+}$species should be able to invade a $\mathrm{HGT}^{-}$population in steady state. In other words, the equilibrium state $\left(C^{-}, N^{-}, C^{+}, N^{+}\right)=\left(\widehat{C}^{-}, \widehat{N}^{-}, 0,0\right)$ should be unstable.

Around the equilibrium $\left(\widehat{C}^{-}, \widehat{N}^{-}, 0,0\right)$, the dynamics of the $\mathrm{HGT}^{+}$-species are linearly approximated by

$$
\left(\begin{array}{c}
\frac{\mathrm{d} C^{+}}{\mathrm{d} t} \\
\frac{\mathrm{d} N^{+}}{\mathrm{d} t}
\end{array}\right) \approx \mathbf{J}\left(\begin{array}{l}
C^{+} \\
N^{+}
\end{array}\right)
$$

where

$$
\mathbf{J}=\left(\begin{array}{cc}
1+b-c h-l-\widehat{\phi} & h \widehat{C}^{-} \\
l & 1-c h-h \widehat{C}^{-}-\widehat{\phi}
\end{array}\right)
$$

The $\mathrm{HGT}^{+}$-species can invade iff the dominant eigenvalue of $\mathbf{J}$ is positive.

Note that the equilibrium densities of $\widehat{C}^{-}$and $\widehat{N}^{-}$depend on $b$ and $l$. As derived in the previous section,

$$
\begin{array}{ll}
\text { if } b \leq l, & \widehat{C}^{-}=0 \quad \text { and } \quad \widehat{N}^{-}=1, \quad \text { while } \\
\text { if } b>l, & \widehat{C}^{-}=1-\frac{l}{b} \quad \text { and } \quad \widehat{N}^{-}=\frac{l}{b} .
\end{array}
$$

We will consider both possibilities separately. 
bioRxiv preprint doi: https://doi.org/10.1101/2020.02.13.947077; this version posted February 16, 2020. The 26

copyright holder for this preprint (which was not certified by peer review) is the author/funder. All rights

reserved. No reuse allowed without permission.

In the case of unrescuable and rescuable genes $(0<b \leq l)$, the equilibrium densities of $\widehat{C}^{-}$and $\widehat{N}^{-}$are given by Eq 31 . Then, $\widehat{\phi}=1$ and the Jacobian matrix

$$
\mathbf{J}=\left(\begin{array}{cc}
b-c h-l & 0 \\
l & -c h
\end{array}\right) .
$$

The eigenvalues of $\mathbf{J}$ are $\lambda_{1}=b-c h-l$ and $\lambda_{2}=-c h$. The second eigenvalue $\lambda_{2}<0$ as long as HGT comes at some cost $c>0$ (the HGT-rate $h$ of a $\mathrm{HGT}^{+}$-species is always positive). At the same time, $\lambda_{1}$ is also negative because we consider genes with a small benefit, $0<b \leq l$. Hence, we conclude that for unrescuable and more importantly for rescuable genes, an $\mathrm{HGT}^{+}$-species cannot invade on a $\mathrm{HGT}^{-}$-population at equilibrium, and HGT can hence never evolve de novo.

In the case of enrichable and indispensable genes $(b>l)$, the equilibrium densities of $\widehat{C}^{-}$and $\widehat{N}^{-}$are given by Eq 32 Now, $\widehat{\phi}=(1+b)\left(1-\frac{l}{b}\right)+\frac{l}{b}=1+b-l$, and the Jacobian matrix

$$
\mathbf{J}=\left(\begin{array}{cc}
-c h & h\left(1-\frac{l}{b}\right) \\
l & l-b-c h-h\left(1-\frac{l}{b}\right)
\end{array}\right) .
$$

The eigenvalues of $\mathbf{J}$ should now be solved from

$$
\begin{array}{r}
(-c h-\lambda)\left(l-b-c h-h\left(1-\frac{l}{b}\right)-\lambda\right)-\operatorname{lh}\left(1-\frac{l}{b}\right)=0 \\
\Longleftrightarrow \lambda^{2}-\lambda\left(l-b-2 c h-h\left(1-\frac{l}{b}\right)\right)+\left(b c h-l c h+c^{2} h^{2}+c^{2}\left(1-\frac{l}{b}\right)-\operatorname{lh}\left(1-\frac{l}{b}\right)\right)=0 .
\end{array}
$$

Let

$$
\begin{aligned}
& \beta=l-b-2 c h-h\left(1-\frac{l}{b}\right), \quad \text { and } \\
& \gamma=b c h-l c h+c^{2} h^{2}+c h^{2}\left(1-\frac{l}{b}\right)-l h\left(1-\frac{l}{b}\right) .
\end{aligned}
$$

Then, the eigenvalues of $\mathbf{J}$ are equal to $\lambda_{1,2}=\frac{1}{2}\left(\beta \pm \sqrt{\beta^{2}-4 \gamma}\right)$. Remember that we are interested in the sign of the dominant eigenvalue. If the eigenvalues are complex $\left(\beta^{2}<4 \gamma\right)$, the real part of the eigenvalues $\operatorname{Re}\left(\lambda_{1,2}\right)>0$ iff $\beta>0$. If the eigenvalues are real, the dominant eigenvalue is $\lambda_{1}=\frac{1}{2}\left(\beta+\sqrt{\beta^{2}-4 \gamma}\right)$, and $\lambda_{1}>0$ iff $\beta>0$ or $\sqrt{\beta^{2}-4 \gamma}>\beta \Longleftrightarrow \gamma<0$. First, consider the possibility $\beta>0$. Then we should have

$$
\begin{aligned}
& l-b-2 c h- h\left(1-\frac{l}{b}\right)>0 \\
& \Longleftrightarrow l-b>h\left(2 c+\left(1-\frac{l}{b}\right)\right) .
\end{aligned}
$$

This is however a contradiction, since we here deal with genes for which $b>l$ and hence $l-b<0$, but $\widehat{C}^{-}=1-\frac{l}{b}>0, c>0$ and $h>0$. Hence, $\beta$ is always negative and the dominant eigenvalue is positive only if $\gamma<0$. From $\gamma<0$, we find

$$
\begin{array}{r}
b c h-l c h+c^{2} h^{2}+c h^{2}\left(1-\frac{l}{b}\right)-l h\left(1-\frac{l}{b}\right)<0 \\
\Longleftrightarrow c(b-l+c h)+(c h-l)\left(1-\frac{l}{b}\right)<0
\end{array}
$$

Trying to solve Eq 40 for any value of $h$ would yield a complicated condition on the value of $b$. However, we can further simplify Eq 40 by asking if a $\mathrm{HGT}^{+}$-species with a very small (but positive) HGT-rate could invade. For $h=\epsilon \approx 0, \mathrm{Eq} 40$ reduces to

$$
c(b-l)-l\left(1-\frac{l}{b}\right)<0,
$$


bioRxiv preprint doi: https://doi.org/10.1101/2020.02.13.947077; this version posted February 16, 2020. The

copyright holder for this preprint (which was not certified by peer review) is the author/funder. All rights

reserved. No reuse allowed without permission.

from which we can solve

$$
\begin{aligned}
& c(b-l)-l\left(1-\frac{l}{b}\right)<0 \\
\Longleftrightarrow & c b^{2}-l(c+1) b+l^{2}<0 \\
\Longleftrightarrow & (c b-l)(b-l)<0 .
\end{aligned}
$$

Since we consider enrichable and indispensable genes, with $b>l$, condition 44 can only be true if $c b<l \Longleftrightarrow b<l / c$, which is exactly the condition that separates enrichable from indispensable genes. Hence, we conclude that for enrichable genes $(l<b<l / c)$, a $\mathrm{HGT}^{+}$-species with a small but positive HGT-rate can always invade on a $\mathrm{HGT}^{-}$-population at equilibrium, and that HGT can hence evolve de novo.

So far, we have determined under what conditions a $\mathrm{HGT}^{-}$-population is evolutionarily stable. We can however ask the same for a $\mathrm{HGT}^{+}$-population. In other words, even though it may not be reached by gradual evolution, can HGT be maintained? To answer this question, we next consider the evolutionary stability of the $\mathrm{HGT}^{+}$-equilibrium: $\left(C^{-}, N^{-}, C^{+}, N^{+}\right)=\left(0,0, \tilde{C}^{+}, \tilde{N}^{+}\right)$.

Again, the densities of $C^{+}$- and $N^{+}$-cells at equilibrium depend on the values of $b, l$ and $h$ (see $\mathrm{Eq} 910$ in the previous section):

$$
\begin{array}{ll}
\text { if } b \leq l-h, & \tilde{C}^{+}=0 \quad \text { and } \quad \tilde{N}^{+}=1, \quad \text { while } \\
\text { if } b>l-h, & \tilde{C}^{+}=1-\frac{l}{b+h} \quad \text { and } \quad \tilde{N}^{+}=\frac{l}{b+h} .
\end{array}
$$

If $b \leq l-h$, the gene does not persist in the population and HGT hence does not confer any benefit, while still imposing a cost on the $N^{+}$-cells. Under these conditions, the $N^{-}$-cells, that do not carry the cost of HGT, will always be able to invade.

For the more interesting case in which the gene does persist in a $\mathrm{HGT}^{+}$-population $(\mathrm{Eq} 46$, we now linearise the dynamics of the $\mathrm{HGT}^{-}$-species around the equilibrium:

$$
\begin{aligned}
& \left(\begin{array}{l}
\frac{\mathrm{d} C^{-}}{\mathrm{d} t} \\
\frac{\mathrm{d} N^{-}}{\mathrm{d} t}
\end{array}\right)=\mathbf{J}\left(\begin{array}{c}
C^{-} \\
N^{-}
\end{array}\right) \\
& \text {with } \mathbf{J}=\left(\begin{array}{cc}
(1+b)-l-\tilde{\phi} & 0 \\
l & 1-\tilde{\phi}
\end{array}\right) \\
& \text { and } \tilde{\phi}=(1+b-c h)\left(1-\frac{l}{b+h}\right)+(1-c h) \frac{l}{b+h}=(1-c h)+b\left(1-\frac{l}{b+h}\right)
\end{aligned}
$$

Again, the $\mathrm{HGT}^{-}$-species can invade if the dominant eigenvalue of $\mathbf{J}$ is positive, and hence the $\mathrm{HGT}^{+}$-species of equilibrium is evolutionarily stable if both eigenvalues are negative. The eigenvalues of $\mathbf{J}$ are $\lambda_{1}=1+b-l-\tilde{\phi}$ and $\lambda_{2}=1-\tilde{\phi}$. 
bioRxiv preprint doi: https://doi.org/10.1101/2020.02.13.947077; this version posted February 16, 2020. The copyright holder for this preprint (which was not certified by peer review) is the author/funder. All rights 28 reserved. No reuse allowed without permission.

For the first eigenvalue, we find

$$
\begin{aligned}
& \lambda_{1}<0 \\
\Longleftrightarrow & 0>1+b-l-\tilde{\phi} \\
\Longleftrightarrow & 0>1+b-l-(1-c h)-b\left(1-\frac{l}{b+h}\right) \\
\Longleftrightarrow & 0>b l+c h(b+h)-l(b+h) \\
\Longleftrightarrow & l h>c h(b+h) \\
\Longleftrightarrow & l>c(b+h) \\
\Longleftrightarrow & c<\frac{l}{b+h}
\end{aligned}
$$

Hence, this first eigenvalue is negative as long as the costs of HGT are not too large.

For the second eigenvalue, we find:

$$
\begin{aligned}
& \lambda_{2}<0 \\
\Longleftrightarrow & 0>1-\tilde{\phi} \\
\Longleftrightarrow & 0>1-(1-c h)-b\left(1-\frac{l}{b+h}\right) \\
\Longleftrightarrow & 0>c h-b\left(1-\frac{l}{b+h}\right) \\
\Longleftrightarrow & c h<b\left(1-\frac{l}{b+h}\right) \\
\Longleftrightarrow & c<\frac{b\left(1-\frac{l}{b+h}\right)}{h} .
\end{aligned}
$$

Remember that we considered a $\mathrm{HGT}^{+}$-population in which the gene can persist, i.e., $b+h>l$. Hence $\frac{l}{b+h}<1$ and the right hand side in Eq 59 is positive. Hence, we can again conclude that there are some non-zero costs for which $\lambda_{2}$ is negative.

Combining the results in Eq 53 and 59 , we see that for some costs, HGT can be maintained. For rescuable genes with costs that satisfy conditions 53 and 59 , there is an Allee effect with respect to HGT: HGT can be evolutionarily maintained, but it cannot evolve de novo. This result can be intuitively understood. Small (invading) $\mathrm{HGT}^{+}$-populations pay the continuous costs for HGT, but hardly ever interact with their conspecifics, and hence the positive fitness effects of maintaining the slightly beneficial gene are too small to overcome the costs for HGT. Higher fitness can only be achieved when the population size is large enough, such that the benefits conferred by HGT outweigh its costs. The presence of an Allee effect was confirmed by numerically integrating $\mathrm{Eq} 2528$ for different initial conditions. We then indeed see that the system converges to different equilibria depending on the initial frequency of $\mathrm{HGT}^{+}$-cells (see Figure 3. 
bioRxiv preprint doi: https://doi.org/10.1101/2020.02.13.947077; this version posted February 16, 2020. The

copyright holder for this preprint (which was not certified by peer review) is the author/funder. All rights

reserved. No reuse allowed without permission.

\section{Part II: Supplementary results and figures}

\section{In the well-mixed IBM, HGT only evolves for enrichable genes}

In the main text we discussed that HGT cannot evolve for genes that cannot persist without HGT. For these genes, a lack of donor cells does not allow mutants that engage in HGT to get a significant fitness benefit, even when they actually do carry the beneficial gene. To get over this so-called Allee effect, a large number of gene-carrying individuals has to simultaneously start engaging in HGT. We have also shown that, in the spatially structure populations, HGT does evolve for genes that could not persist without HGT, as it is more likely that the lack of donor cells is, at least locally, overcome. This supplementary figure summarises this result, by showing that, even though HGT does evolve for enrichable genes under well-mixed conditions, it indeed fails to evolve for rescuable genes. 
bioRxiv preprint doi: https://doi.org/10.1101/2020.02.13.947077; this version posted February 16, 2020. The copyright holder for this preprint (which was not certified by peer review) is the author/funder. All rights 30 reserved. No reuse allowed without permission.

A) HGT evolution for an enrichable gene ( $b=0.03$, well-mixed)

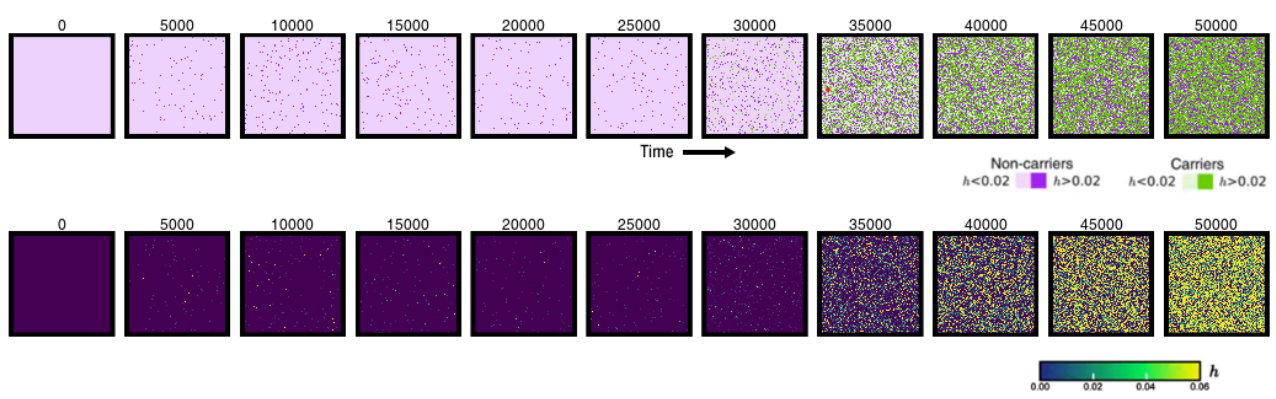

B) HGT evolution for a rescuable gene ( $b=0.0175$, well-mixed)

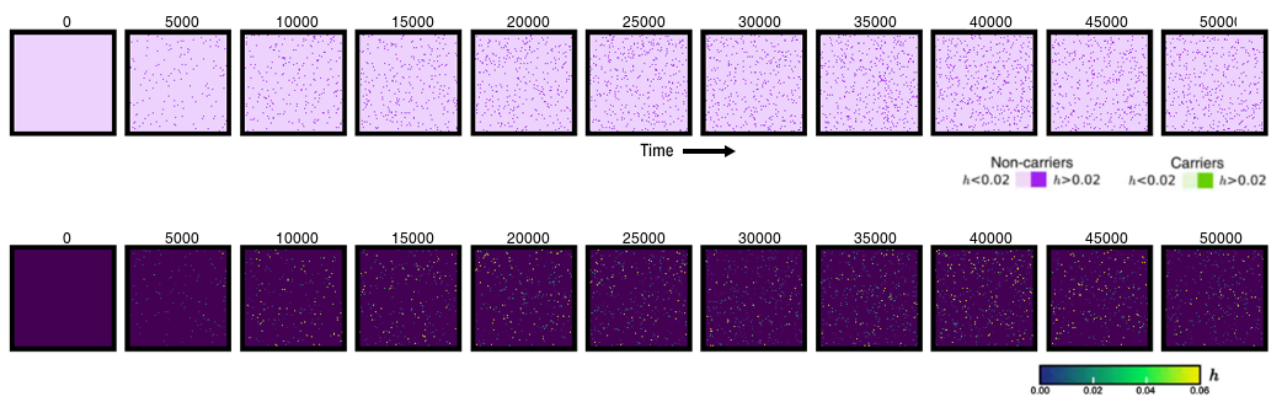

C) HGT evolution for a rescuable gene ( $b=0.03$, no mixing)
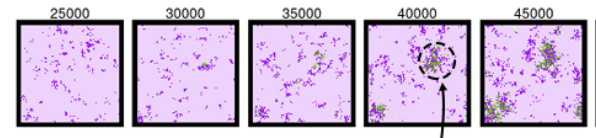

local "nucleation"
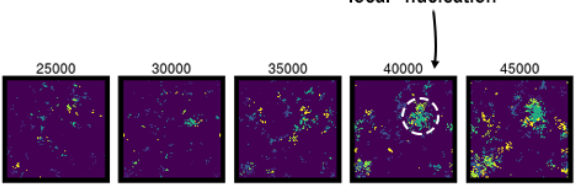
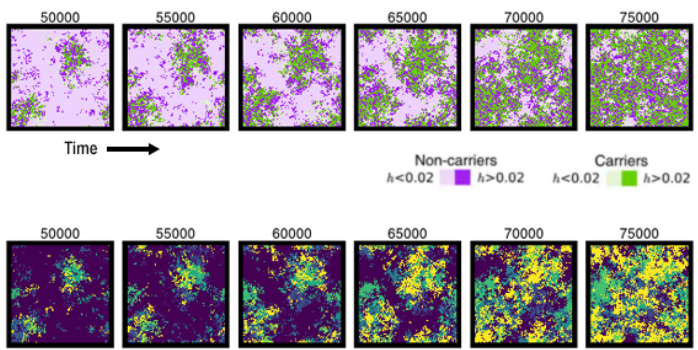

Figure S1: HGT evolution in IBM under various conditions 
bioRxiv preprint doi: https://doi.org/10.1101/2020.02.13.947077; this version posted February 16, 2020. The copyright holder for this preprint (which was not certified by peer review) is the author/funder. All rights reserved. No reuse allowed without permission.

\section{Maintaining weak and strong Selfish Genetic Elements}

In the main text we have discussed how SGEs can coexist along-side their hosts and slightly beneficial genes, even when the their fitness-penalty is greater than the benefit of the gene. However, this was only observed in the spatially structured model, as illustrated in the figure below.

\section{A) Cartoon of the 4 cell types}
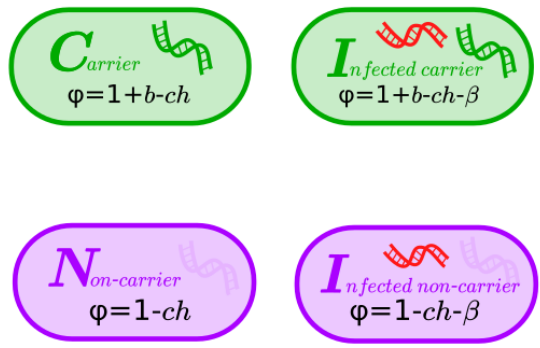

\section{B) Persistence of SGEs}

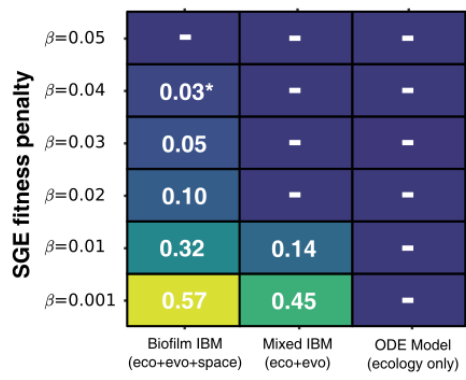

SGE freq $\mathrm{h}_{\text {evolved }}$ in IBM

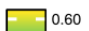

$-0.45$

$-0.30$

$-0.15$

* in small populations as used here, co-evolution between the hosts HGT-rate and SGEs may cause extinction.

Larger grids as shown in the main text are more resilient to this.

C) SGEs with intermediate fitness penalty impose the highest cost on the host (simulated in the spatially structured populations of $200 \times 200$ cells)

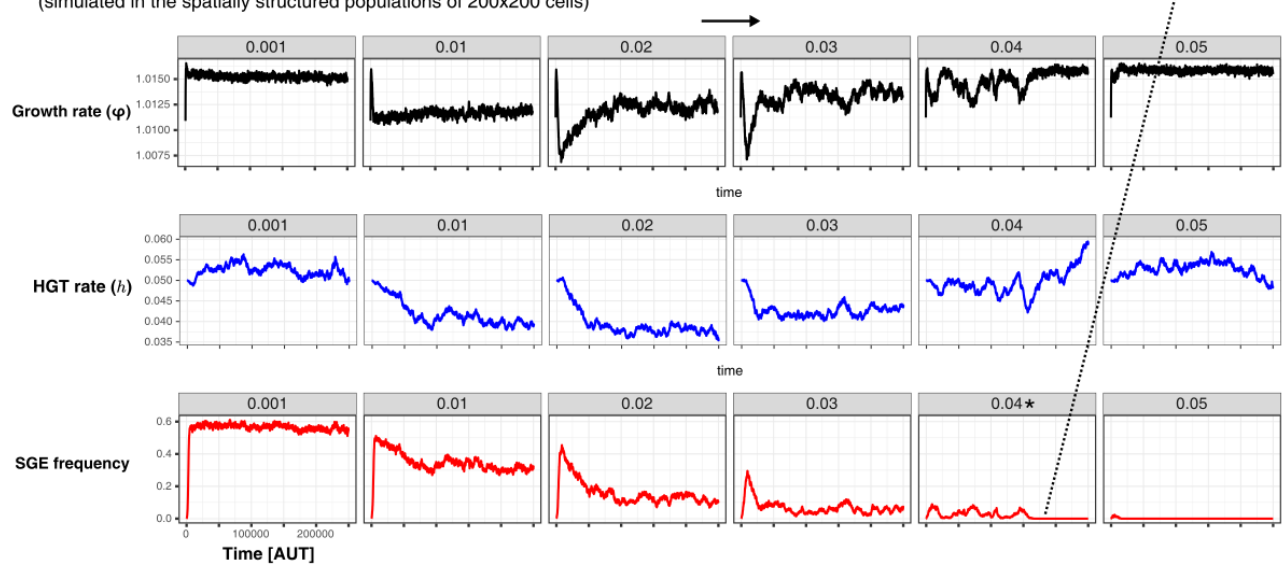

Figure S 2: Persistence of SGEs in various implementations of our model. A shows a cartoon of the cell types, between which competition was modelled in a various ways. In B we show for these different implementations how many SGEs persist within the populations for SGEs with different penalties. For the IBM, we simulated for 250.000 time steps and calculated the average SGE-frequency in the final 100 generations. For the ODE model, we chose the optimal rate of HGT $\left(h_{o p t}\right)$, and numerically integrated the equilibrium concentrations of infected cells. Finally, C shows the temporal dynamics of the growth rate $(\phi)$, HGT-rate $(h)$, and the SGE frequency, in the spatially structured simulations. As this parameter sweep had slighly smaller populations sizes as used in the main text, the strong SGE could eventually go extinct (this is annotated with an asterisk). 
bioRxiv preprint doi: https://doi.org/10.1101/2020.02.13.947077; this version posted February 16, 2020. The 32 reserved. No reuse allowed without permission.

\section{Equations for Supplementary Figure $\mathrm{S} 2 \mathrm{~A}$}

$$
\begin{aligned}
\frac{\mathrm{d} C}{\mathrm{~d} t} & =\gamma(1+b-c h) C-l C+l D+h(N C+0.5 N D-C P-C D)-\phi C \\
\frac{\mathrm{d} N}{\mathrm{~d} t} & =\gamma(1-c h) N+l C+l P-h N(C+P+D)-\phi N \\
\frac{\mathrm{d} P}{\mathrm{~d} t} & =\gamma(1-\beta-c h) P+l D-l P+h(N P+N D / 2-C P-P D)-\phi P \\
\frac{\mathrm{d} D}{\mathrm{~d} t} & =\gamma(1+b-\beta-c h) D-l D 2+h(C P+C D+P C+P D)-\phi D \\
\phi & =\gamma((1+b-c h) C+(1-c h) N+(1-\beta-c h) P+(1+b-\beta-c h) D)
\end{aligned}
$$


bioRxiv preprint doi: https://doi.org/10.1101/2020.02.13.947077; this version posted February 16, 2020. The copyright holder for this preprint (which was not certified by peer review) is the author/funder. All rights reserved. No reuse allowed without permission.

\section{Strong SGEs fail to spread / persist in the population at low HGT-distances}

In the main text we have discussed how we found that strong SGEs (genetic parasites with a greater penalty than the beneficial gene) could nevertheless stably coexist with an evolving population of cells. However, this persistence of SGEs relies on their ability to escape to new susceptible hosts who have not experienced SGEs for some time (and therefore have evolved elevated HGT rates). In this supplementary figure, it is indeed seen how the distance influences the spread / persistence of SGEs. If the distance between donor and acceptor is very local $(d=1)$, SGEs cannot spread even while they are still fluxing in (top row). For an intermediate HGT-distance $(1<d<10)$, the SGEs persist for a bit as long as they flux in, but die out when influx is stopped (middle row). For larger HGT distances $(d>10)$, we found that SGEs can persist even after the influx was stopped.
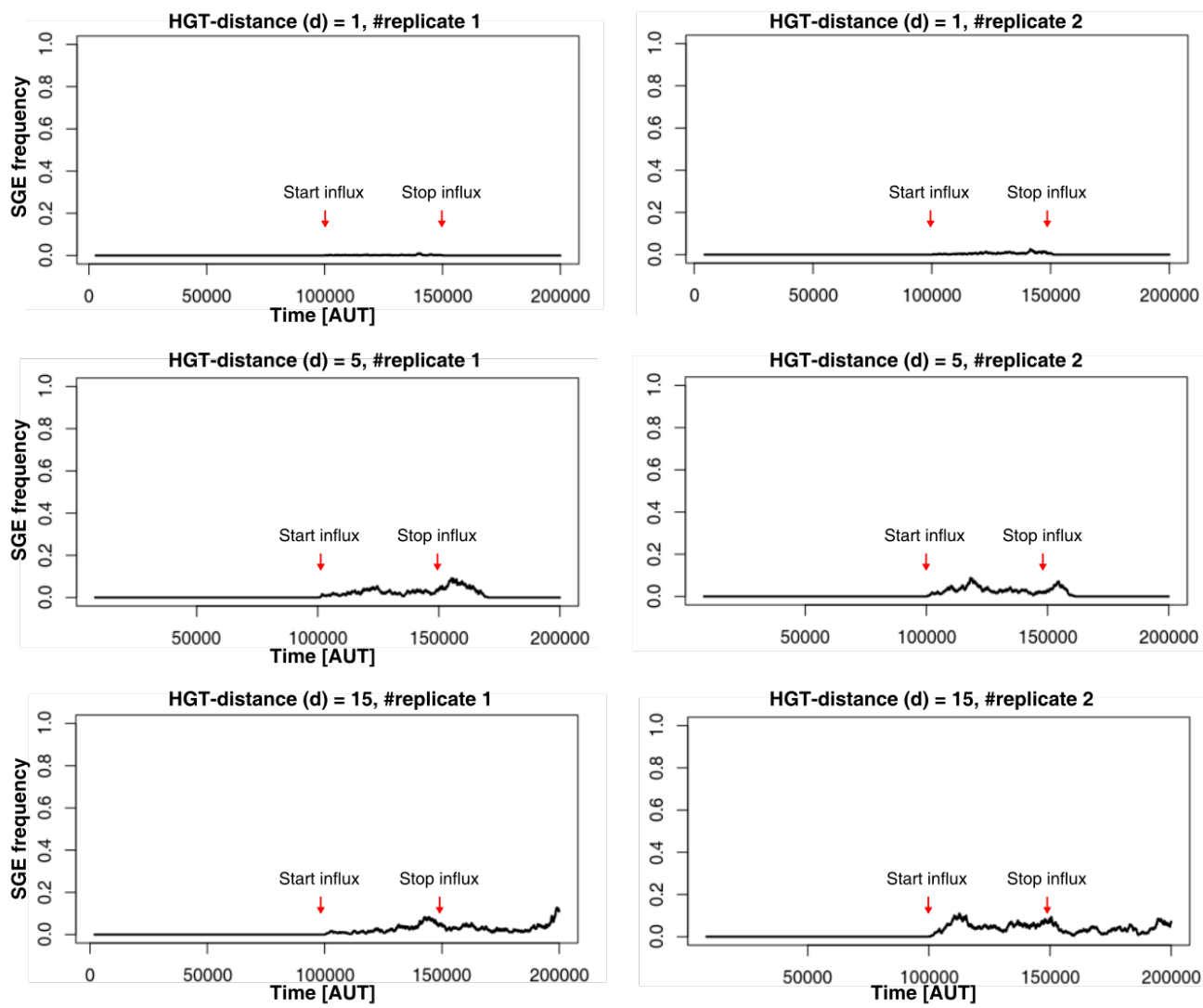

Figure S3: SGEs persistance in open and closed ecosystems. Parameters used: 
bioRxiv preprint doi: https://doi.org/10.1101/2020.02.13.947077; this version posted February 16, 2020. The copyright holder for this preprint (which was not certified by peer review) is the author/funder. All rights 34 reserved. No reuse allowed without permission.

\section{Supplementary Movie - Gene-sharing 'nucleation events' and coexistence with SGEs}

This annotated supplementary movie illustrates how gene-sharing of rescuable genes emerges through a 'nucleation'-event, allowing local communities eventually overgrow all other cells. Where a local sub-community initially transitions to the alternative $H G T^{+}$state, eventually the whole population will be taken over. Similar mechanisms have been observed in origin of life studies Wu and Higgs (2012) and microbial community transitions Kotil and Vetsigian (2018). We also show here how SGEs (here with $b=0.01$ ) are able to infect, and stably coexist, with this gene-transferring community.

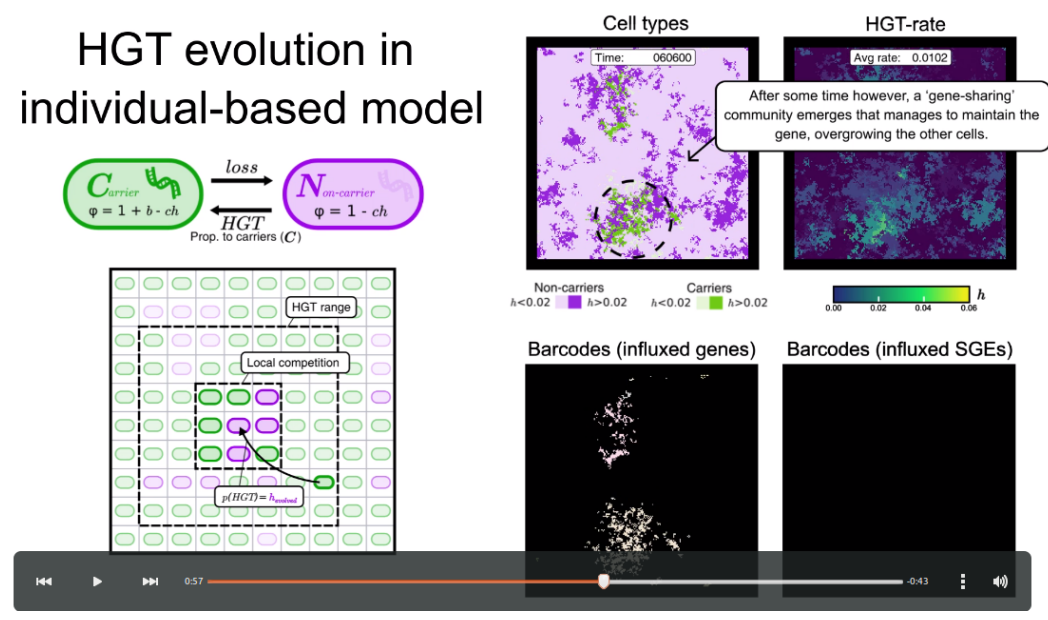

Figure S4: A snapshot from the supplementary movie. 
bioRxiv preprint doi: https://doi.org/10.1101/2020.02.13.947077; this version posted February 16, 2020. The copyright holder for this preprint (which was not certified by peer review) is the author/funder. All rights reserved. No reuse allowed without permission.

\section{Bibliography}

A. N. N. Ba, I. Cvijović, J. I. R. Echenique, K. R. Lawrence, A. Rego-Costa, X. Liu, S. F. Levy, and M. M. Desai. High-resolution lineage tracking reveals travelling wave of adaptation in laboratory yeast. Nature, 575(7783):494-499, 2019.

D. A. Baltrus. Exploring the costs of horizontal gene transfer. Trends in ecology $\&$ evolution, 28(8):489-495, 2013.

T. Bataillon. Estimation of spontaneous genome-wide mutation rate parameters: whither beneficial mutations? Heredity, 84(5):497, 2000.

C. W. Beitel, L. Froenicke, J. M. Lang, I. F. Korf, R. W. Michelmore, J. A. Eisen, and A. E. Darling. Strain-and plasmid-level deconvolution of a synthetic metagenome by sequencing proximity ligation products. PeerJ, 2:e415, 2014.

C. T. Bergstrom, M. Lipsitch, and B. R. Levin. Natural selection, infectious transfer and the existence conditions for bacterial plasmids. Genetics, 155(4):1505-1519, 2000.

J. R. Blundell and S. F. Levy. Beyond genome sequencing: lineage tracking with barcodes to study the dynamics of evolution, infection, and cancer. Genomics, 104(6):417-430, 2014.

J. N. Burton, I. Liachko, M. J. Dunham, and J. Shendure. Species-level deconvolution of metagenome assemblies with hi-c-based contact probability maps. G3: Genes, Genomes, Genetics, 4(7):1339-1346, 2014.

E. Casacuberta and J. González. The impact of transposable elements in environmental adaptation. Molecular ecology, 22(6):1503-1517, 2013.

J. M. Chacón and W. R. Harcombe. Increasing growth rate slows adaptation when genotypes compete for diffusing resources. Unpublished data,bioRxiv, page 616938, 2019.

S. C. Choi, M. D. Rasmussen, M. J. Hubisz, I. Gronau, M. J. Stanhope, and A. Siepel. Replacing and additive horizontal gene transfer in streptococcus. Molecular biology and evolution, 29(11):3309-3320, 2012.

O. X. Cordero, L.-A. Ventouras, E. F. DeLong, and M. F. Polz. Public good dynamics drive evolution of iron acquisition strategies in natural bacterioplankton populations. Proceedings of the National Academy of Sciences, 109(49):20059-20064, 2012.

T. Dimitriu, F. Medaney, E. Amanatidou, J. Forsyth, R. J. Ellis, and B. Raymond. Negative frequency dependent selection on plasmid carriage and low fitness costs maintain extended spectrum $\beta$-lactamases in escherichia coli. Scientific Reports, 9(1):1-7, 2019.

W. F. Doolittle and O. Zhaxybayeva. On the origin of prokaryotic species. Genome research, 19(5):744-756, 2009. 
bioRxiv preprint doi: https://doi.org/10.1101/2020.02.13.947077; this version posted February 16, 2020. The copyright holder for this preprint (which was not certified by peer review) is the author/funder. All rights 36 reserved. No reuse allowed without permission.

Y. Gerardin, M. Springer, and R. Kishony. A competitive trade-off limits the selective advantage of increased antibiotic production. Nature microbiology, 1(12):16175, 2016.

I. Gordo and P. R. Campos. Adaptive evolution in a spatially structured asexual population. Genetica, 127(1-3):217, 2006.

M. G. Habets, T. Czaran, R. F. Hoekstra, and J. A. G. De Visser. Spatial structure inhibits the rate of invasion of beneficial mutations in asexual populations. Proceedings of the Royal Society B: Biological Sciences, 274(1622):2139-2143, 2007.

J. P. Hall, A. J. Wood, E. Harrison, and M. A. Brockhurst. Source-sink plasmid transfer dynamics maintain gene mobility in soil bacterial communities. Proceedings of the National Academy of Sciences, 113(29):8260-8265, 2016.

W. Hao and G. B. Golding. The fate of laterally transferred genes: life in the fast lane to adaptation or death. Genome Research, 16(5):636-643, 2006.

J.-H. Hehemann, P. Arevalo, M. S. Datta, X. Yu, C. H. Corzett, A. Henschel, S. P. Preheim, S. Timberlake, E. J. Alm, and M. F. Polz. Adaptive radiation by waves of gene transfer leads to fine-scale resource partitioning in marine microbes. Nature communications, 7:12860, 2016.

P. T. Inc. Collaborative data science, 2015. URL https://plot.ly.

J. Iranzo, Y. I. Wolf, E. V. Koonin, and I. Sela. Gene gain and loss push prokaryotes beyond the homologous recombination barrier and accelerate genome sequence divergence. Nature Communications, 10(1):1-10, 2019.

R. Jain, M. C. Rivera, J. E. Moore, and J. A. Lake. Horizontal gene transfer accelerates genome innovation and evolution. Molecular biology and evolution, 20(10):1598-1602, 2003.

Y. F. P. Job. Gnu parallel: The command-line power tool.

J.-N. Kim, Y. Kim, Y. Jeong, J.-H. Roe, B.-G. Kim, and B.-K. Cho. Comparative genomics reveals the core and accessory genomes of streptomyces species. J Microbiol Biotechnol, 25 (10):1599-605, 2015.

S. E. Kotil and K. Vetsigian. Emergence of evolutionary stable communities through eco-evolutionary tunneling. bioRxiv, page 271015, 2018.

C.-H. Kuo and H. Ochman. Deletional bias across the three domains of life. Genome biology and evolution, 1:145-152, 2009.

T. Lefébure and M. J. Stanhope. Evolution of the core and pan-genome of streptococcus: positive selection, recombination, and genome composition. Genome biology, 8(5):R71, 2007.

J. Lerner, M. Manhart, W. Jasinska, L. Gauthier, A. W. Serohijos, and S. Bershtein. Chromosomal barcoding of e. coli populations reveals lineage diversity dynamics at high resolution. bioRxiv, page 571505, 2019.

S. F. Levy, J. R. Blundell, S. Venkataram, D. A. Petrov, D. S. Fisher, and G. Sherlock. Quantitative evolutionary dynamics using high-resolution lineage tracking. Nature, 519 (7542):181, 2015.

F. Li, M. L. Salit, and S. F. Levy. Unbiased fitness estimation of pooled barcode or amplicon sequencing studies. Cell systems, 7(5):521-525, 2018. 
bioRxiv preprint doi: https://doi.org/10.1101/2020.02.13.947077; this version posted February 16, 2020. The

copyright holder for this preprint (which was not certified by peer review) is the author/funder. All rights

BIBLIOGRAPHY

reserved. No reuse allowed without permission.

L. N. Lili, N. F. Britton, and E. J. Feil. The persistence of parasitic plasmids. Genetics, 177(1): 399-405, 2007.

A. J. Lopatkin, S. Huang, R. P. Smith, J. K. Srimani, T. A. Sysoeva, S. Bewick, D. K. Karig, and L. You. Antibiotics as a selective driver for conjugation dynamics. Nature microbiology, 1(6):16044, 2016.

M. Lynch, J. Conery, and R. Bürger. Mutational meltdowns in sexual populations. Evolution, 49(6):1067-1080, 1995.

M. Lynch, M. S. Ackerman, J.-F. Gout, H. Long, W. Sung, W. K. Thomas, and P. L. Foster. Genetic drift, selection and the evolution of the mutation rate. Nature Reviews Genetics, 17 (11):704, 2016.

J. S. Madsen, M. Burmølle, L. H. Hansen, and S. J. Sørensen. The interconnection between biofilm formation and horizontal gene transfer. FEMS Immunology $\& 3$ Medical Microbiology, 65(2):183-195, 2012.

S. E. Mc Ginty, D. J. Rankin, and S. P. Brown. Horizontal gene transfer and the evolution of bacterial cooperation. Evolution: International Journal of Organic Evolution, 65(1):21-32, 2011.

J. C. Mell and R. J. Redfield. Natural competence and the evolution of dna uptake specificity. Journal of bacteriology, 196(8):1471-1483, 2014.

J. A. Metz, S. A. Geritz, G. Meszéna, F. J. Jacobs, and J. S. Van Heerwaarden. Adaptive dynamics: a geometrical study of the consequences of nearly faithful reproduction. 1995.

J. J. Morris, R. E. Lenski, and E. R. Zinser. The black queen hypothesis: evolution of dependencies through adaptive gene loss. MBio, 3(2):e00036-12, 2012.

H. J. Muller. The relation of recombination to mutational advance. Mutation Research/Fundamental and Molecular Mechanisms of Mutagenesis, 1(1):2-9, 1964.

P. Nazarian, F. Tran, and J. Q. Boedicker. Modeling multispecies gene flow dynamics reveals the unique roles of different horizontal gene transfer mechanisms. Frontiers in microbiology, 9:2978, 2018.

R. Niehus, S. Mitri, A. G. Fletcher, and K. R. Foster. Migration and horizontal gene transfer divide microbial genomes into multiple niches. Nature communications, 6:8924, 2015.

T. Nogueira, D. J. Rankin, M. Touchon, F. Taddei, S. P. Brown, and E. P. Rocha. Horizontal gene transfer of the secretome drives the evolution of bacterial cooperation and virulence. Current Biology, 19(20):1683-1691, 2009.

A. Novick and W. F. Doolittle. Horizontal persistence and the complexity hypothesis. Biology E Philosophy, 35(1):2, 2020.

R. W. Nowell, S. Green, B. E. Laue, and P. M. Sharp. The extent of genome flux and its role in the differentiation of bacterial lineages. Genome biology and evolution, 6(6):1514-1529, 2014.

H. Ochman, J. G. Lawrence, and E. A. Groisman. Lateral gene transfer and the nature of bacterial innovation. nature, 405(6784):299, 2000.

P. Puigbò, A. E. Lobkovsky, D. M. Kristensen, Y. I. Wolf, and E. V. Koonin. Genomes in turmoil: quantification of genome dynamics in prokaryote supergenomes. BMC biology, 12 (1):66, 2014 . 
bioRxiv preprint doi: https://doi.org/10.1101/2020.02.13.947077; this version posted February 16, 2020. The copyright holder for this preprint (which was not certified by peer review) is the author/funder. All rights 38 reserved. No reuse allowed without permission.

S. D. Quistad, G. Doulcier, and P. B. Rainey. Experimental manipulation of selfish genetic elements links genes to microbial community function. BioRxiv, page 608752, 2019.

D. J. Rankin, E. P. Rocha, and S. P. Brown. What traits are carried on mobile genetic elements, and why? Heredity, 106(1):1, 2011.

R. J. Redfield. Do bacteria have sex? Nature Reviews Genetics, 2(8):634, 2001.

M. A. Riley and J. E. Wertz. Bacteriocins: evolution, ecology, and application. Annual Reviews in Microbiology, 56(1):117-137, 2002.

T. Sakoparnig, C. Field, and E. van Nimwegen. Whole genome phylogenies reflect long-tailed distributions of recombination rates in many bacterial species. bioRxiv, page 601914, 2019.

S. T. Schultz and M. Lynch. Mutation and extinction: the role of variable mutational effects, synergistic epistasis, beneficial mutations, and degree of outcrossing. Evolution, 51(5): 1363-1371, 1997.

B. J. Shapiro, J. Friedman, O. X. Cordero, S. P. Preheim, S. C. Timberlake, G. Szabó, M. F. Polz, and E. J. Alm. Population genomics of early events in the ecological differentiation of bacteria. science, 336(6077):48-51, 2012.

F. R. Slater, M. J. Bailey, A. J. Tett, and S. L. Turner. Progress towards understanding the fate of plasmids in bacterial communities. FEMS Microbiology Ecology, 66(1):3-13, 2008.

B. Snel, P. Bork, and M. A. Huynen. Genomes in flux: the evolution of archaeal and proteobacterial gene content. Genome research, 12(1):17-25, 2002.

K. Soetaert, T. Petzoldt, and R. W. Setzer. Solving differential equations in R: Package deSolve. Journal of Statistical Software, 33(9):1-25, 2010. ISSN 1548-7660. doi: 10.18637/jss.v033.i09. URL http://www. jstat.soft.org/v33/i09

S. M. Soucy, J. Huang, and J. P. Gogarten. Horizontal gene transfer: building the web of life. Nature Reviews Genetics, 16(8):472-482, 2015.

T. Stalder, B. Cornwell, J. Lacroix, B. Kohler, S. Dixon, H. Yano, B. Kerr, L. J. Forney, and E. M. Top. Evolving populations in biofilms contain more persistent plasmids. Molecular Biology and Evolution, 2020.

N. Takeuchi, K. Kaneko, and E. V. Koonin. Horizontal gene transfer can rescue prokaryotes from muller's ratchet: benefit of dna from dead cells and population subdivision. G3: Genes, Genomes, Genetics, 4(2):325-339, 2014.

N. Takeuchi, O. X. Cordero, E. V. Koonin, and K. Kaneko. Gene-specific selective sweeps in bacteria and archaea caused by negative frequency-dependent selection. BMC biology, 13(1): 20,2015 .

C. M. Thomas and K. M. Nielsen. Mechanisms of, and barriers to, horizontal gene transfer between bacteria. Nature reviews microbiology, 3(9):711, 2005.

T. Toffoli and N. Margolus. Cellular automata machines: a new environment for modeling (scientific computation). In Press Cambridge, page 259. 1987.

M. Touchon, C. Hoede, O. Tenaillon, V. Barbe, S. Baeriswyl, P. Bidet, E. Bingen, S. Bonacorsi, C. Bouchier, O. Bouvet, et al. Organised genome dynamics in the escherichia coli species results in highly diverse adaptive paths. PLoS genetics, 5(1):e1000344, 2009. 
bioRxiv preprint doi: https://doi.org/10.1101/2020.02.13.947077; this version posted February 16, 2020. The

copyright holder for this preprint (which was not certified by peer review) is the author/funder. All rights

BIBLIOGRAPHY

reserved. No reuse allowed without permission.

T. J. Treangen and E. P. Rocha. Horizontal transfer, not duplication, drives the expansion of protein families in prokaryotes. PLoS genetics, 7(1):e1001284, 2011.

B. van Dijk and P. Hogeweg. In silico gene-level evolution explains microbial population diversity through differential gene mobility. Genome biology and evolution, 8(1):176-188, 2015.

Z. Vig-Milkovics, I. Zachar, Á. Kun, A. Szilágyi, and E. Szathmáry. Moderate sex between protocells can balance between a decrease in assortment load and an increase in parasite spread. Journal of theoretical biology, 462:304-310, 2019.

A. A. Vogan and P. G. Higgs. The advantages and disadvantages of horizontal gene transfer and the emergence of the first species. Biology direct, 6(1):1, 2011.

T. Vogwill and R. C. MacLean. The genetic basis of the fitness costs of antimicrobial resistance: a meta-analysis approach. Evolutionary applications, 8(3):284-295, 2015.

M. Vos, M. C. Hesselman, T. A. te Beek, M. W. van Passel, and A. Eyre-Walker. Rates of lateral gene transfer in prokaryotes: high but why? Trends in microbiology, 23(10):598-605, 2015 .

M. Vos, A. Buckling, and B. Kuijper. Sexual selection in bacteria? Trends in microbiology, 2019.

R. A. Welch, V. Burland, G. Plunkett, P. Redford, P. Roesch, D. Rasko, E. Buckles, S.-R. Liou, A. Boutin, J. Hackett, et al. Extensive mosaic structure revealed by the complete genome sequence of uropathogenic escherichia coli. Proceedings of the National Academy of Sciences, 99(26):17020-17024, 2002.

H. Wickham. ggplot2: Elegant Graphics for Data Analysis. Springer-Verlag New York, 2016. ISBN 978-3-319-24277-4. URL https://ggplot2.tidyverse.org.

J. Wiedenbeck and F. M. Cohan. Origins of bacterial diversity through horizontal genetic transfer and adaptation to new ecological niches. FEMS microbiology reviews, 35(5):957-976, 2011.

M. J. Wiser and R. E. Lenski. A comparison of methods to measure fitness in escherichia coli. PLoS One, 10(5):e0126210, 2015.

M. Wu and P. G. Higgs. The origin of life is a spatially localized stochastic transition. Biology direct, 7(1):42, 2012.

E. Yaffe and D. A. Relman. Tracking microbial evolution in the human gut using hi-c reveals extensive horizontal gene transfer, persistence and adaptation. Nature Microbiology, 5(2): 343-353, 2020. 